\title{
Engineering Structures
}

\section{Efficacy of roof-to-beam mechanical connections on the diaphragm behaviour of precast decks with spaced roof elements}

\author{
Bruno Dal Lago* and Liberato Ferrara \\ Politecnico di Milano, Department of Civil and Environmental Engineering \\ Piazza Leonardo da Vinci 32, 20133, Milan, Italy
}

*Corresponding author; brunoalberto.dallago@polimi.it

\begin{abstract}
The diaphragm action of slab/roof decks ensures the collaboration of different parts of the lateral load resisting system of a building. In reinforced concrete precast buildings for industrial/commercial halls, not seldom the deck is not provided with a cast-in-situ topping: this results into diaphragm action to rely upon the floor mechanical connections alone. In this study, the effectiveness of three different typical floor-beam connections, namely hot-rolled angle brackets, cold-formed angle brackets and dowel bars, on the diaphragm action of the deck has been investigated. To this purpose, simplified macroscopic "behaviour models" have been proposed, based on the results of monotonic and cyclic tests carried out within the framework of the research project Safecast (FP7-SME-2007-2; GA 218417/2009). A numerical model of a dry-assembled precast structure with mechanical floor-to-beam connections has been checked against the results of cyclic and pseudodynamic tests carried out on a full-scale prototype within the framework of the Precast Structures EC8 project (GA G6RD-CT-2002-70002). Non-linear dynamic analyses have then been performed to investigate the diaphragm action effectiveness of the three different technological solutions to connect slab and beams as above considering a seismic action orthogonal to the roof elements. Different stiffness distributions of the lateral load resisting system have been considered, investigating the possible bracing effect induced by an integrated connection system of the external cladding panels. A simplified "design-wise" analytical interpretation of the phenomenon is also formulated and checked against the numerical results.
\end{abstract}

Keywords Precast Concrete; Seismic Performance; Roof-to-Beam Connections; Diaphragm Action; Pseudo-Dynamic Testing; Non-Linear Analysis; Seismic Design.

\section{Highlights}

- A numerical model is checked against seismic tests on a precast structure

- Simplified macro-models of typical dry roof-beam connections are proposed

- Analyses are carried out on precast structures with various deck connections

- Different stiffness distributions of the LLRS are also considered

- An analytical seismic design method for deck connections and structure is proposed 


\section{Introduction}

The seismic behaviour of precast frame buildings is affected by the diaphragm effectiveness of the floor/roof decks [01-06]. In partially-precast concrete buildings, for which in-situ concrete casting is required for completion after assemblage, a structural concrete topping is often present. The deck provided with structural topping, if the latter is correctly reinforced and detailed, features a large diaphragm stiffness, and can be assumed as rigid, following the rules of the main structural codes [07,08]. The seismic behaviour of the decks in partially-precast structures was investigated in [0913], mainly with reference to typical multi-storey parking facilities built in the USA. A design framework for partially precast structures was set in [14-18]. Tailored tests on topping connections were performed by [19,20] and full-scale prototype testing was performed by [21].

As a matter of fact, in several European countries, dry-assembled precast structures, which are assembled without any in-situ concrete casting following the concept of the maximum industrialisation of the precast product, are much more common.

In this type of structures, the diaphragm effectiveness has to rely only upon the mechanical connections of the floor/roof decks. Not seldom the roof decks are made with spaced elements, to allow zenith lighting of the buildings, (Figure 1), which, preventing mutual floor-floor connections to be installed, may also result in jeopardised effectiveness of the diaphragm action.

The seismic behaviour of the decks of dry-assembled precast structures lacks an in-depth investigation. Preliminary studies on the subject are available in [22-25]. The most typical floor-beam connections consist of angle brackets for TT elements and dowels for other types of elements, such as the wing-shaped ones [26,27]. Tests on typical and tailored floor-beam mechanical connections have been reported in [28] and [29], respectively. Tests on dowel connections are reported in [30-35]. Design rules for these connections were proposed in [36]. The results of cyclic and pseudo-dynamic tests on full-scale prototypes of precast structures with dry-assembled diaphragms are reported in [3744].

In this study, the effectiveness on the diaphragm action of three different typical floor-beam connections, namely hot-rolled angle brackets, cold-formed angle brackets and dowel bars has been investigated. To this purpose simplified macroscopic "behaviour models" have been proposed, based on the results of tests carried out within the framework of the research project Safecast (FP7-SME2007-2; GA 218417/2009). A numerical model of a dry-assembled precast structure with mechanical floor-to-beam connections has been checked against the results of cyclic and pseudo-dynamic tests carried out on a full-scale prototype within the framework of the Precast Structures EC8 project (GA 
G6RD-CT-2002-70002). Non-linear dynamic analyses have then been performed to investigate the diaphragm action effectiveness of the three different technological solutions to connect floor and beams as above. This paper deals with the case of a seismic action orthogonal to the roof elements only.

The earthquake induced actions on the diaphragm depend on the homogeneity of distribution of mass and stiffness among the different frames of the structure. A possible in-plane seismic interaction of the cladding panels with the frame [24,45-48] may lead to a non-uniform distribution of stiffness among the peripheral and inner frames, inducing higher stress in the diaphragm or causing relevant deck distortions. This restraint condition and its effects on the diaphragm effectiveness is also investigated in this paper.

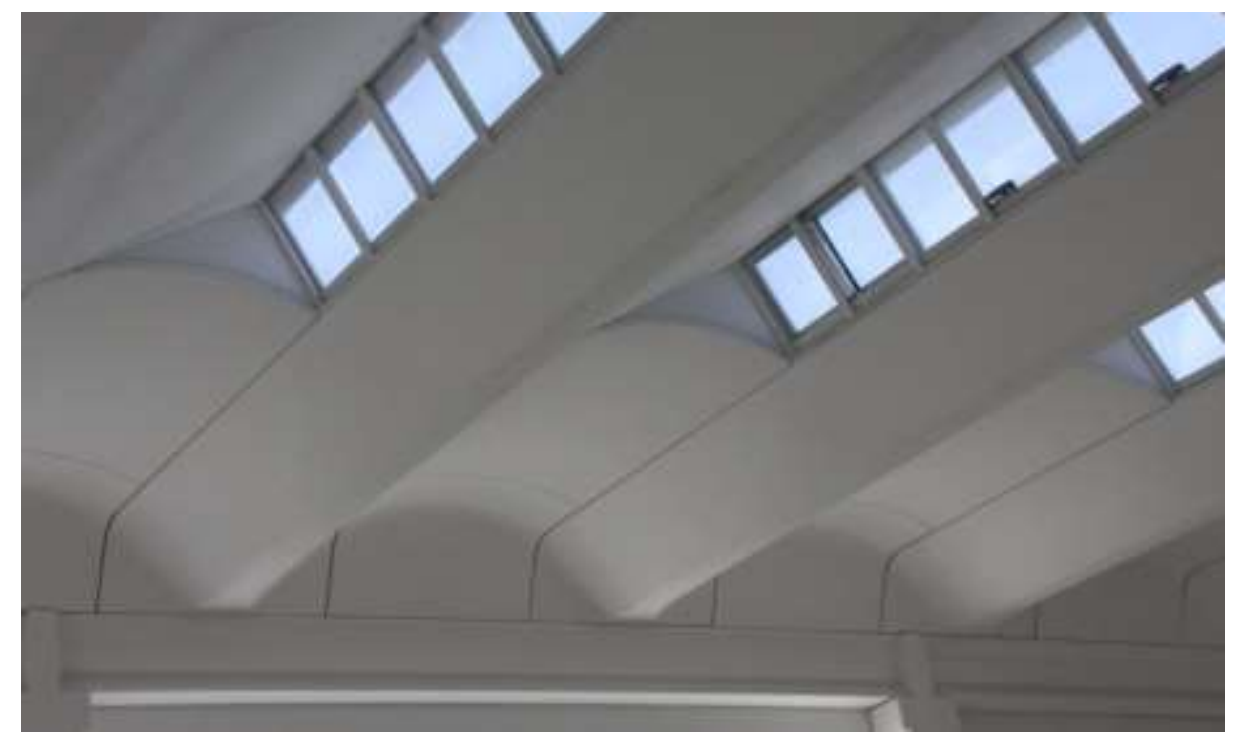

FIGURE 1. Roof of precast dry-assembled industrial building made with spaced wing-shaped elements with zenith light openings

Three typical mechanical roof-beam connections have been considered in the present work. They are: (i) hot-rolled angle brackets (Figure 2a), made by cutting thick hot-rolled steel profiles and connected by post-inserted anchors to the beam and by a threaded bar to the roof element; (ii) cold-formed angle brackets (Figure 2b), made by bending steel plates at right angle and connected by post-inserted anchors to the beam and by a threaded bar to the roof element; (iii) dowels (Figure 2c), vertically protruding from the beam and inserted into a pocket left into the roof element, generally completed with cast-in-situ mortar. 


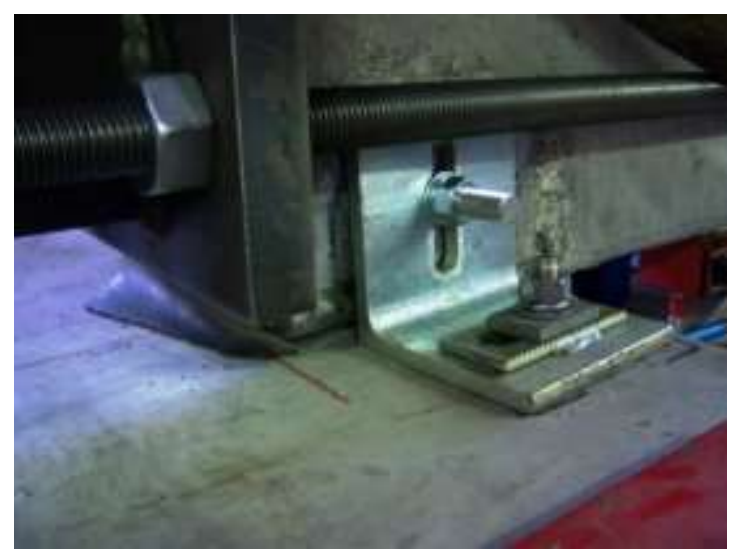

(a)

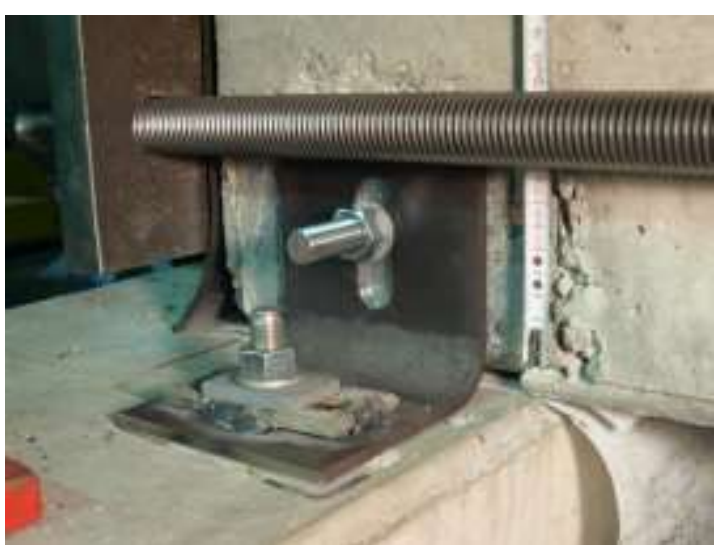

(b)

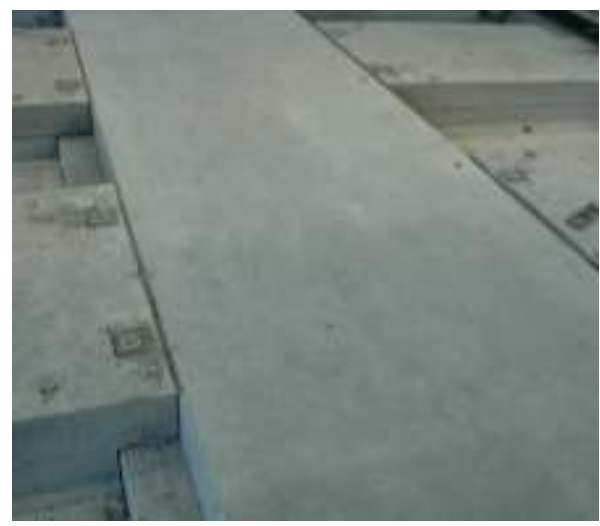

(c)

FIGURE 2. Typical roof-beam connections: (a) hot-rolled angles, (b) cold-formed angles, (c) dowels

\section{Numerical model and comparison with results from full-scale prototype tests}

The seismic performance of precast structures with different deck connections and restraint conditions has been investigated by means of dynamic non-linear analyses with imposed seismic accelerograms performed on numerical models. The modelling technique shall take into account various peculiarities of the seismic behaviour of precast frame structures, including the non-linear behaviour of the columns, the offset position of superposed structural elements, the second order effects, and the specific behaviour of the connections. The modelling technique has been compared against the experimental results of cyclic and pseudo-dynamic tests on a full-scale prototype of dryassembled precast industrial structure performed at the ELSA laboratory of the Joint Research Centre of the European Commission, located in Ispra, Italy. This experimental program was carried out in the framework of the Precast Concrete EC8 research project funded by the European Commission. The building consists of three parallel portal frames made by columns and beams. The roof elements are placed orthogonally to the beams, in a number of three for each of the two bays. The structural 
layout of the building is shown in Figure 3a. Geometric details of the structural elements are given in Figure $3 \mathrm{~b}$. A picture of the prototype is also shown in Figure 3c. The six columns have 400x400 mm square section and a clear height of $5 \mathrm{~m}$. They are reinforced with $8 \Phi 16$ bars placed at the corners and at mid-side, corresponding to $1 \%$ of geometrical reinforcement ratio. The three beams, placed on a single $8 \mathrm{~m}$ span nave, have I cross-section and are $65 \mathrm{~cm}$ deep.

The six TT roof elements are $50 \mathrm{~cm}$ deep and cover the two bays of $8 \mathrm{~m}$ each. Two actuators were connected at the roof level to the reaction wall of the laboratory. Steel load repartition beams were linked to the actuators and welded to steel plates embedded in all roof elements. Both bare and cladded frame configurations were tested. Typical mechanical connections used in practice were tested. They consisted of pocket column-foundation, pinned beam-column, hot-rolled angle brackets roof-beam and strap/anchor channel vertical panel-beam connections. Further details on the prototype and on the experimental results are available in [37-39].

Structural analysis software Midas-Gen [50] has been employed for numerical modelling. Each structural element of the frame has been modelled with beam elements. Beam and roof elements have been modelled as elastic, since they are not expected to exceed the elastic limit during the earthquake. A smeared plasticity fibre non-linear model has been attributed to the columns. The Mander model [51] has been used for both confined and unconfined class C45/55 concrete fibres. The Menegotto and Pinto model [52] has been used for grade B500H steel fibres.

The real position of the overlapped structural elements has been taken into account with a saddletype model (Figure 4). In this model, horizontal rigid links connect the centre of mass of the roof element to the vertical axis of the centroids of the ribs. The vertical distance between centres of mass of roof and beam is made up by two connection elements, one per rib, to which linear or non-linear force-displacement relationships can be attributed in all directions, simulating the behaviour of the mechanical connections. For the comparison of the numerical model against the experimental results, an elastic stiffness of $25 \mathrm{kN} / \mathrm{mm}$ has been used to model the hot-rolled angle connections placed in the prototype. Such a value has been derived from the first elastic branch (pre-activation) observed in the tests described in [28].

The experimental programme was divided into three phases: (i) pseudo-dynamic tests on the bare frame structure; (ii) pseudo-dynamic tests on the cladded frame structure; (iii) cyclic test on the bare frame structure. 


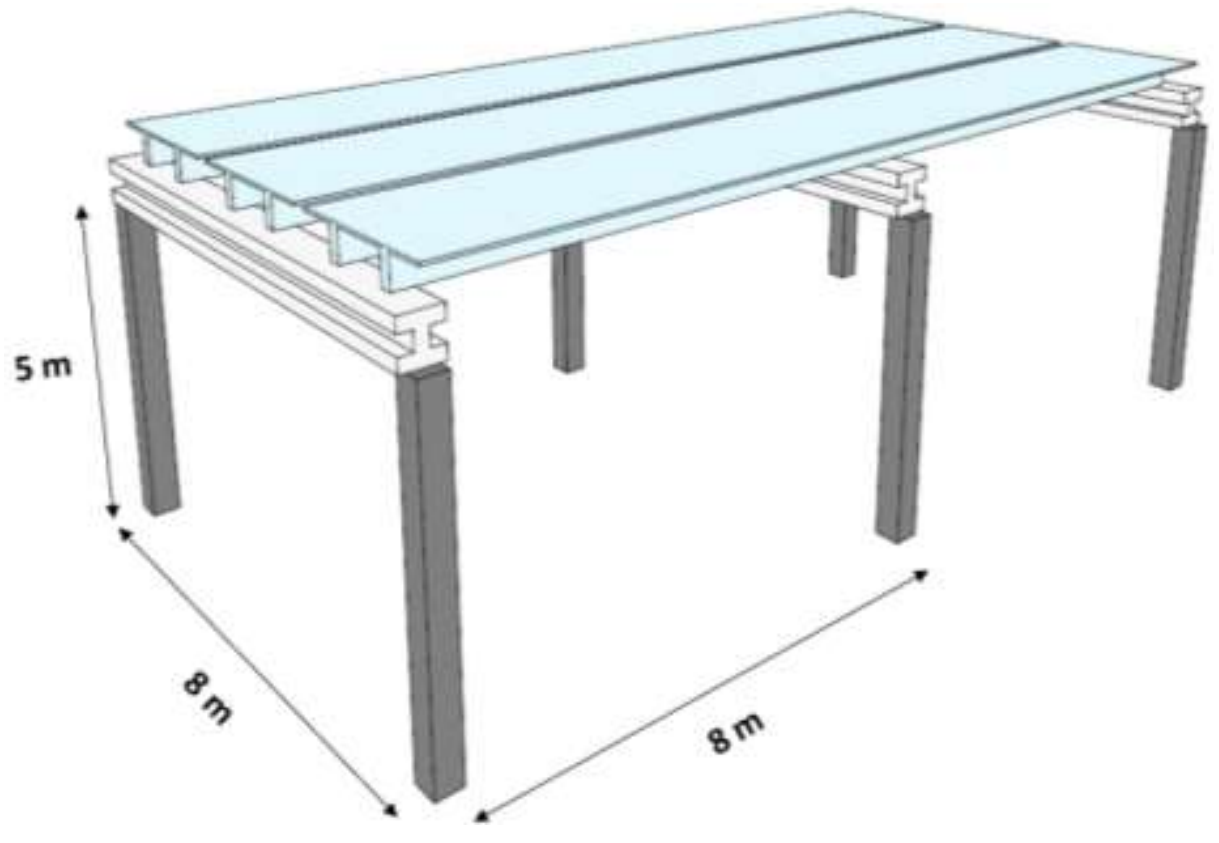

(a)

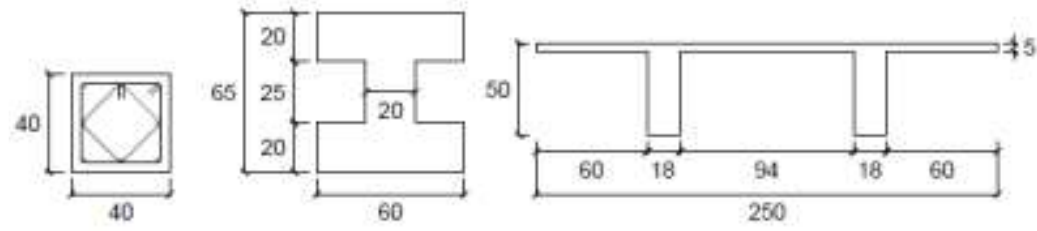

(b)

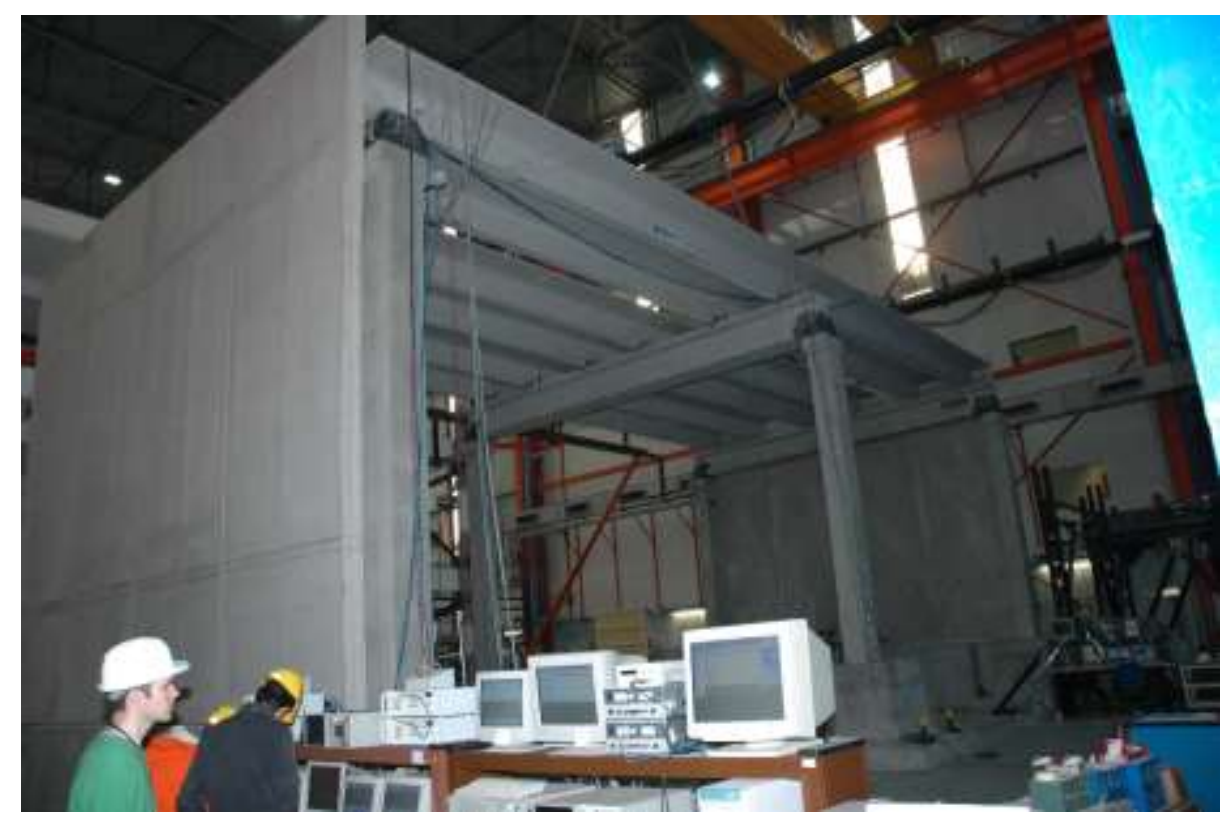

(c)

FIGURE 3. Full-scale prototype of precast building subjected to experimental assessment: (a) structural layout, (b) structural elements [cm], (c) assembled prototype under testing 

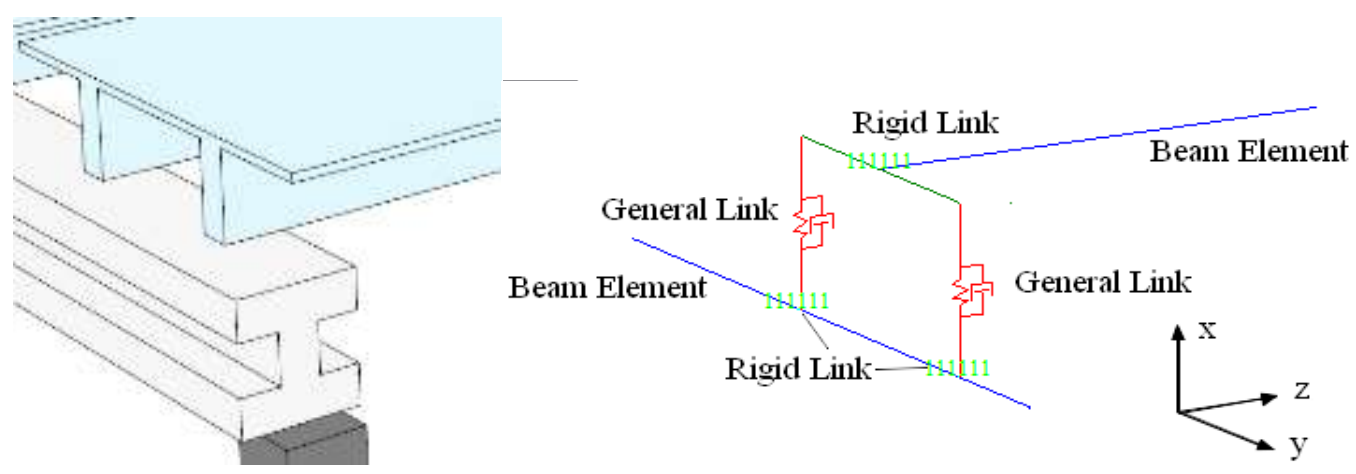

FIGURE 4. Saddle modelling of roof-beam joint

The results of the cyclic test carried out during the experimental phase (iii) on the prototype are reported in Figure 5, compared with the numerical results obtained by imposing a displacement at mid-span of the roof elements, consistently with the experimental load apparatus. A remarkable correspondence of the results is observed, which are also able to correctly describe the progressive stiffness degradation due to yielding of the reinforcing bars, which results into a low stiffness at the displacement reversal. As a matter of fact, before a plastic compressive strain is activated that makes the crack to close and restores the concrete contribution to the cross-section stiffness, only the bars are acting in compression.

The artificial accelerogram spectrum compatible with that from the EC8 shown in Figure 6a was used in the experimental campaign to carry out the seismic tests using the pseudo-dynamic technique.

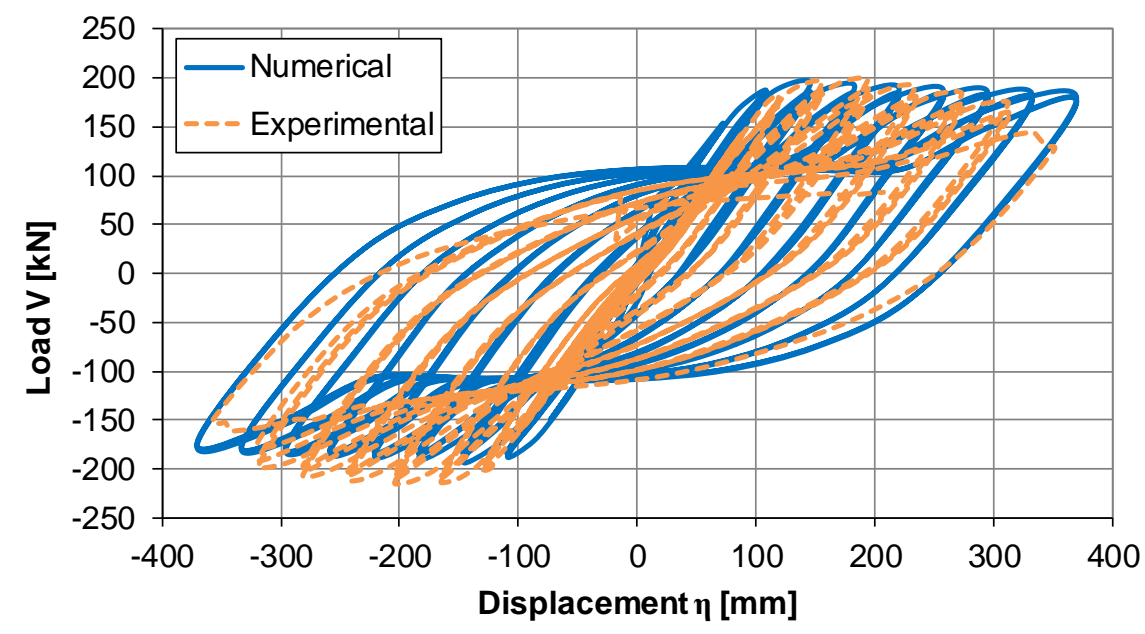

FIGURE 5. Cyclic behaviour of the prototype: experimental vs numerical results 


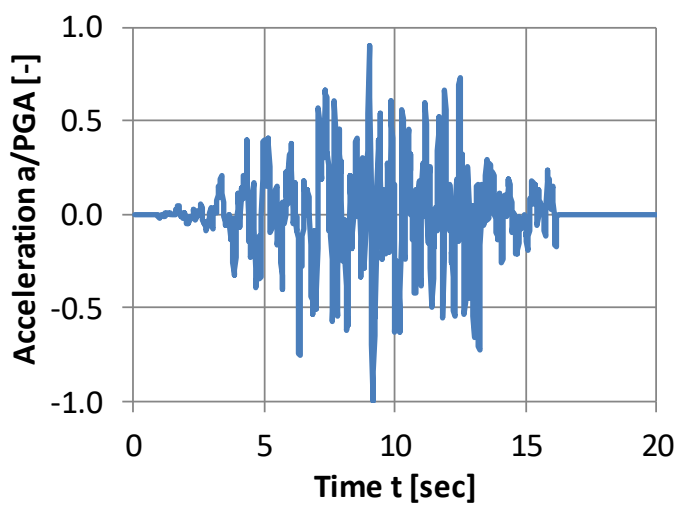

(a)

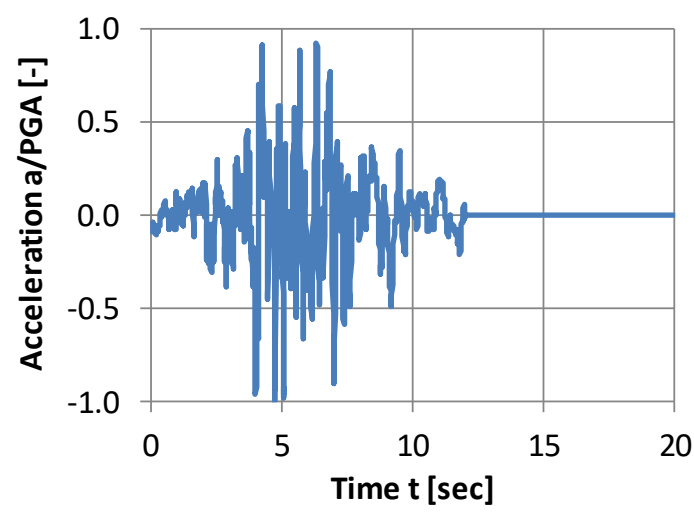

(b)

FIGURE 6. Seismic input spectrum compatible accelerograms: (a) artificially generated (accelerogram 1), (b) artificially modified from the natural signal recorded at Tolmezzo (Friuli earthquake, Italy, 1976 - accelerogram 2)

During the phase (i), the prototype was subjected to the accelerogram (1) scaled at increasing PGAs. The vibratory response of the prototype is reported in Figure 7 for PGAs of $0.14 \mathrm{~g}, 0.35 \mathrm{~g}$ and $0.525 \mathrm{~g}$, respectively, with reference to the central frame displacement. The structural behaviour is characterised by a remarkable flexibility, with maximum experimental displacements of 57, 117 and $159 \mathrm{~mm}$ associated to each of the applied accelerograms. The maximum base shear of the central frame was measured equal to 18,30 and $33 \mathrm{kN}$, respectively. The results of the numerical simulations performed with a damping factor of $5 \%$ are overlapped to the experimental in Figure 7 . The comparison of the results of the $0.14 \mathrm{~g}$ test highlights an underestimation of the maximum displacement of the numerical model. This should be attributed to the negligible influence of the precracking stiffer branch in the seismic response of the specimen, which vibrates practically according to the cracked stiffness only, whilst the numerical model shows a stiffer initial branch associated to the non-cracked section due to the influence of the axial load. This effect plays a decreasing role with increasing PGAs. The numerical results of the tests with higher PGAs indicates that the non-linear dynamic behaviour is matched by the model with good approximation (Figure 7b, 7c). 


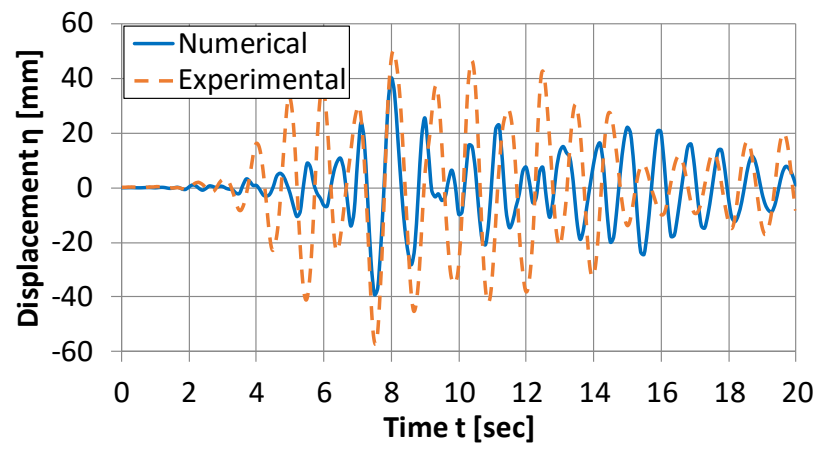

(a)

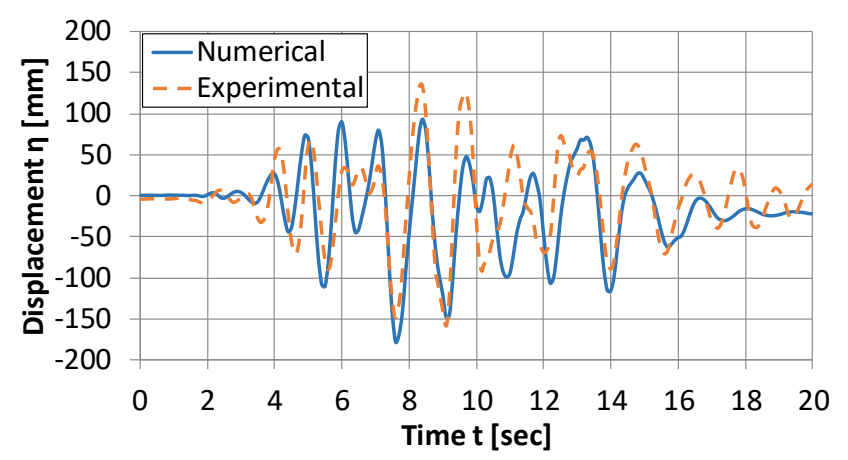

(c)

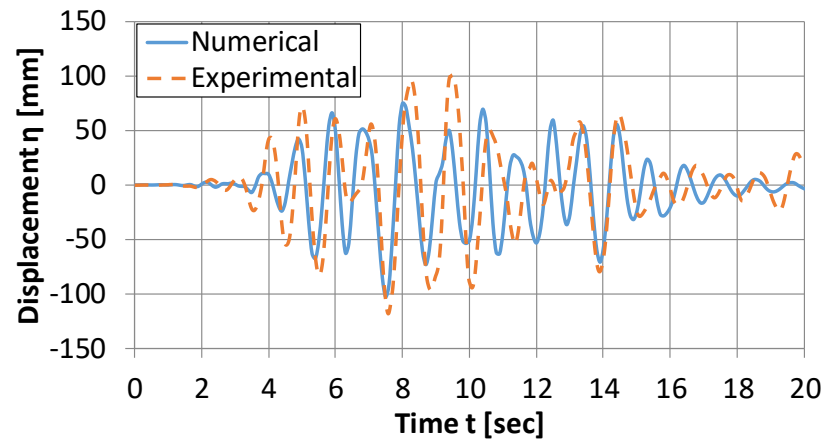

(b)

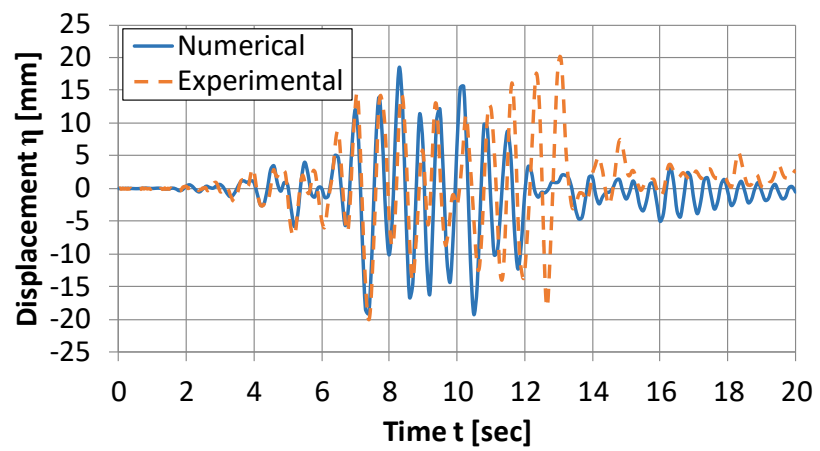

(d)

FIGURE 7. Experimental and numerical top displacement time histories of the central frame of the prototype under accelerogram scaled at PGA equal to (a) $0.14 \mathrm{~g}$, (b) $0.35 \mathrm{~g}$, (c) $0.525 \mathrm{~g}$ for bare frame structure, (d) $0.14 \mathrm{~g}$ for cladded frame structure

At the beginning of phase (ii), vertical $\mathrm{r} / \mathrm{c}$ cladding panels were installed besides the external frames simply leaning on their foundation and connected to the beams with classical channel profiles placed in couples (see [53] for details on this connection). The experimental results related to a PGA equal to $0.14 \mathrm{~g}$ are reported in Figure $7 \mathrm{~d}$. The frame-cladding interaction gave a remarkable stiffening of the structure due to the bracing effect of the panels as a consequence of the in-plane stress induced from the panel-beam connection. The effect of the added stiffness is noticeable from the shorter vibration period and the reduced maximum displacement attained, equal to about $20 \mathrm{~mm}$, corresponding to about one third of that attained in the same test on the bare frame structure. This also indicates a good diaphragm behaviour. The experimental curves are compared with the results of the numerical analyses carried out under the assumption of fixed external frames. A good correspondence of the results is attained up to about 11 seconds, after which the uplift of the cladding panels rocking over their base occurred, which could not be caught by the model. 


\section{Non-linear modelling assumptions for the roof-beam connections}

The non-linear mechanical behaviour of the typical roof-beam connections has been calibrated on the basis of experimental evidence, so to investigate their role in the seismic performance of precast structures through non-linear dynamic analyses. From the test results described in [28], the experimental behaviour of post-inserted 10-mm thick hot-rolled angle brackets placed at both sides of a rib and connected through a bolt may be described with:

(a) a stiff initial phase, up to about $5 \mathrm{kN}$, where the activation of the kinematics of the connection is hampered by friction,

(b) a softer linear branch due to the activation and deformation of the connection up to around $12 \mathrm{kN}$,

(c) a further harder linear branch due to the over-strength of the connection up to its functional limit, equal to about $70 \mathrm{kN}$.

The hysteresis during branch (b) is characterised by cycles with large area, while the area within the cycles decreases when entering the branch (c) due to the influence of the rigid body rotation of the angle upon unloading, which causes a pinching effect.

The proposed simplified macro-model (Figure 8a) is characterised by an elastic-plastic behaviour with inflection at $5 \mathrm{kN}$ and a linear hardening branch with an average stiffness with respect to those of phases (b) and (c), equal to $2.4 \mathrm{kN} / \mathrm{mm}$. A kinematic hardening rule is assigned, which, while showing a good matching with phase (b), may under-estimate the dissipation of energy for phase (c). More sophisticated hysteretic laws might better define the behaviour of this connection. However, reference has been made to common hysteretic laws available in most of the structural software used by practitioners.

From the results of tests described in detail in [28], the experimental behaviour of 5-mm thick postinserted cold-formed angle brackets placed at both sides of a rib and connected by a bolt may be described with:

(a) a stiff initial phase, up to about $5 \mathrm{kN}$, where the activation of the kinematics of the connection is hampered by friction,

(b) a single softer linear branch due to the activation and deformation of the connection under combined shear, flexure and torsion up to its functional displacement limit, to which corresponds a load of about $30 \mathrm{kN}$.

The hysteresis during branch (b) is characterised by yielding of the steel and stable dissipation of energy with negligible pinching effects. 
The proposed macro-model (Figure $8 \mathrm{~b}$ ) is elastic up to the inflection $5 \mathrm{kN}$ point, followed by a plastic branch with stiffness equal to $1.1 \mathrm{kN} / \mathrm{mm}$. The kinematic hardening hysteretic model correctly fits the experimental results.

The hysteretic behaviour of a dowel connection has been calibrated on the basis of the results of the cyclic test reported in [33] on a 25-mm dowel bar inserted into elements cast with a proper confinement provided by $\Phi 12 / 50$ horizontal hooks and $100 \mathrm{~mm}$ of concrete cover. The monotonic curve is characterised by:

(a) a stiff elastic phase up to the yield load of about $75 \mathrm{kN}$,

(b) a plateau characterised by yielding of the dowel. The plastic hysteresis is characterised by the tendency to reach the reverse load point after the elastic unloading branch.

The proposed macro-model (Figure 8c) is elastic-plastic with initial stiffness of $28.9 \mathrm{kN} / \mathrm{mm}$ and constant post-yield load of $75 \mathrm{kN}$. The Takeda hysteretic model [48] is in good agreement with the experimental observations.

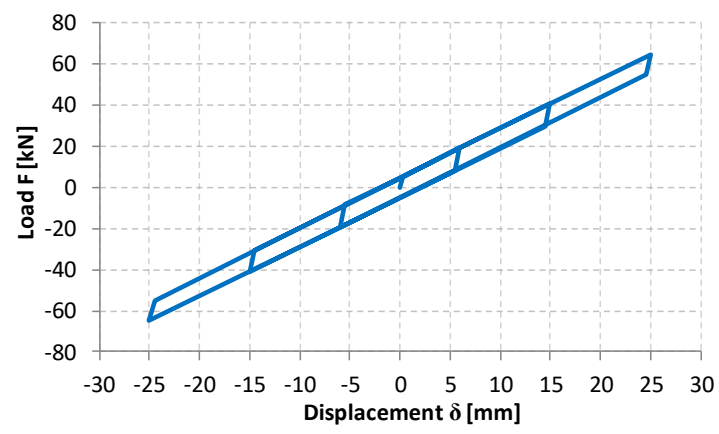

(a)

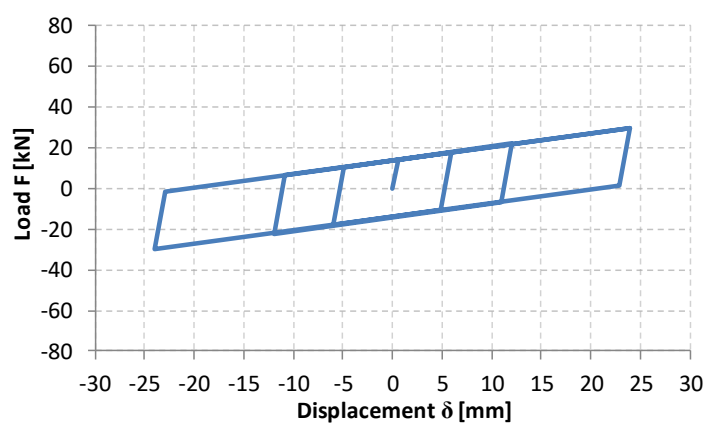

(b)

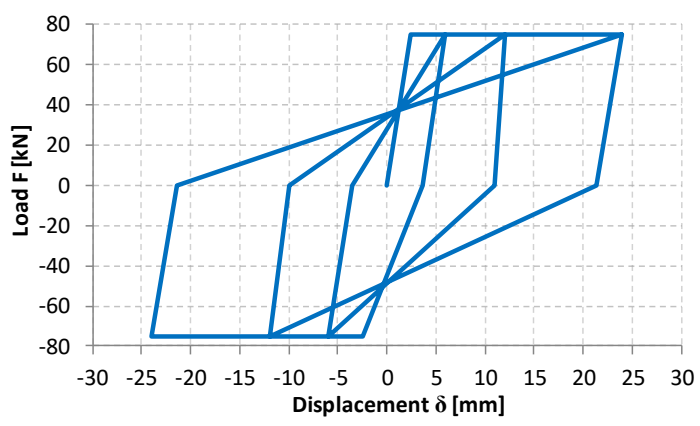

(c)

FIGURE 8. Proposed cyclic behaviour laws for typical roof-beam connections: (a) hot-rolled angles, (b) cold-formed angles, (c) dowels 


\section{Non-linear dynamic analysis on the test prototype with different connections}

The results of the non-linear dynamic analyses on the bare frame model with different roof-to-beam connections under the accelerogram 2 (Figure 6b) artificially modified from the natural signal registered at Tolmezzo (Italy-1976) in order to match the EC8 response spectrum are shown in Figure 9 for a PGA of $0.525 \mathrm{~g}$ and in Figure 10 for a PGA of $0.7 \mathrm{~g}$. It clearly appears that only dowel connections are able to guarantee full activation of diaphragm action. On the other hand, when angle brackets are employed, a distortion of the diaphragm not accompanied with out-of-phase vibration is evidenced.

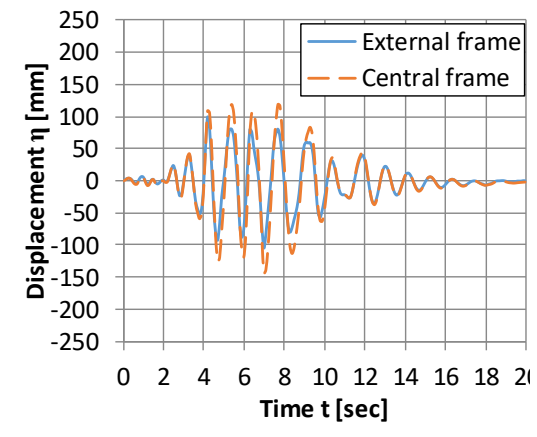

(a)

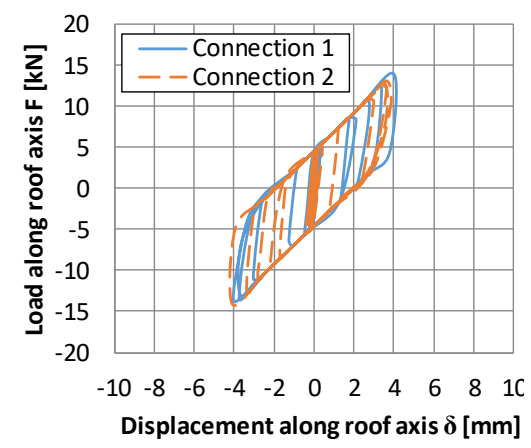

(d)

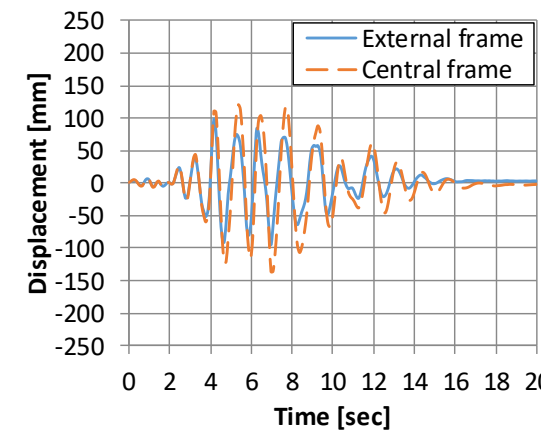

(b)

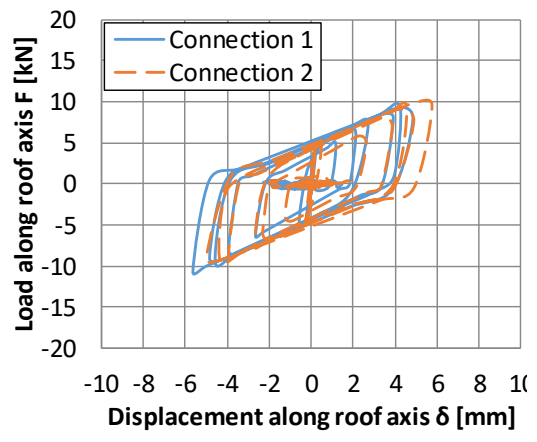

(e)

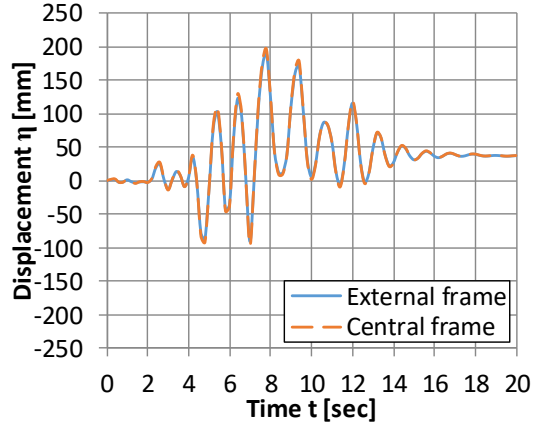

(c)

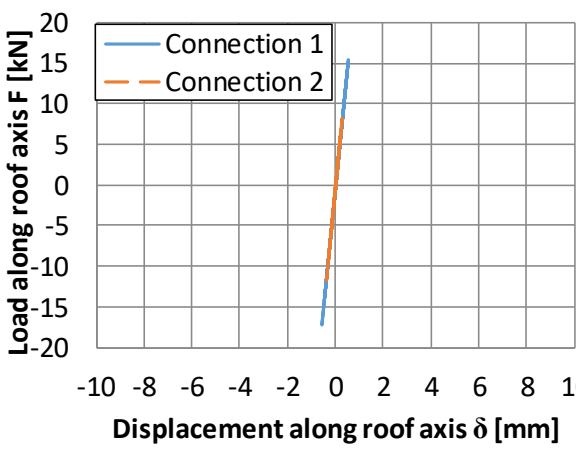

(f)

FIGURE 9. Analysis on bare frame with PGA $=0.525 \mathrm{~g}$ : vibratory curves with (a) hot rolled angle, (b) cold formed angle, (c) dowel, and corresponding hysteresis of a couple of (d) hot rolled angle, (e) cold formed angle, (f) dowel roof-to-beam connections 


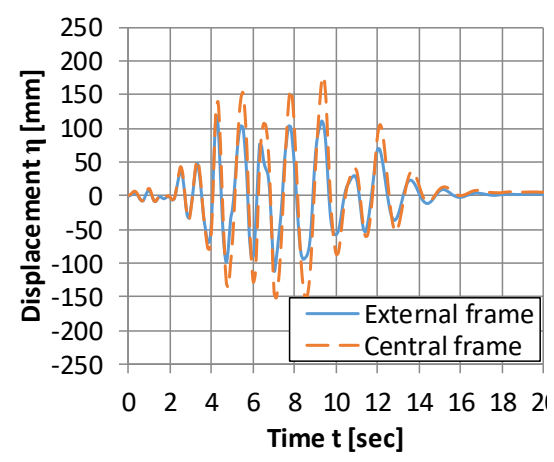

(a)

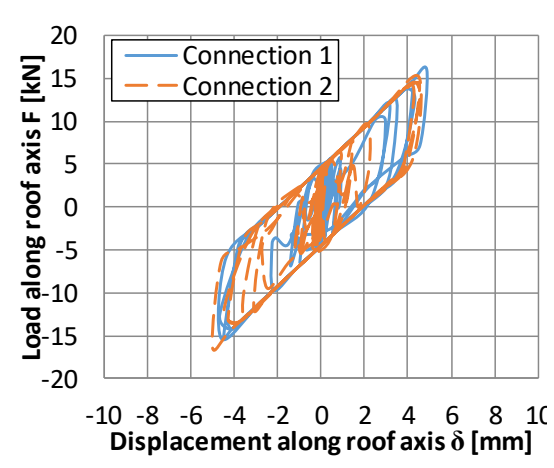

(d)

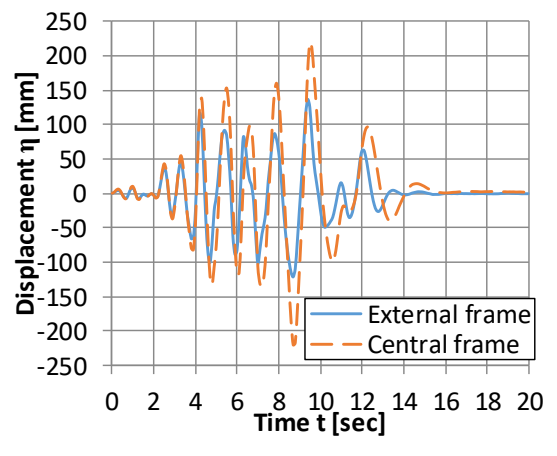

(b)

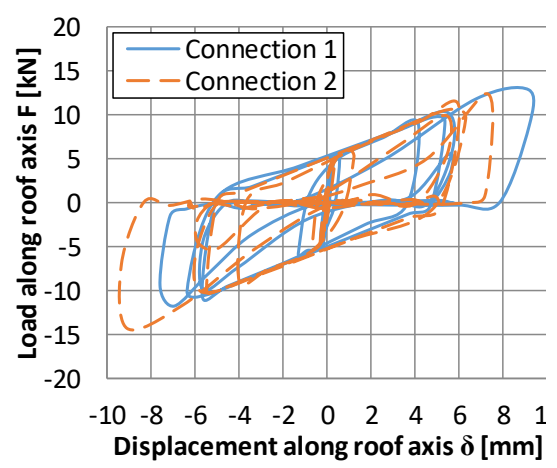

(e)

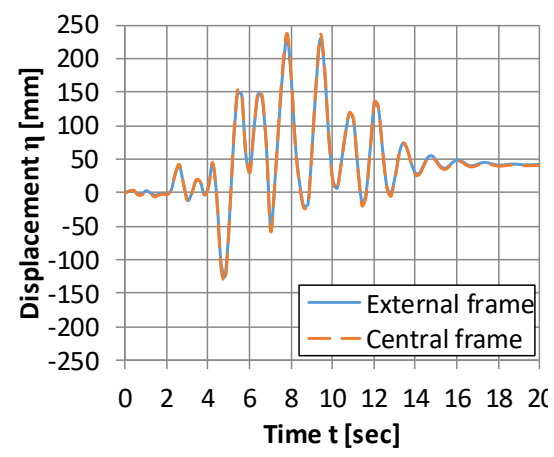

(c)

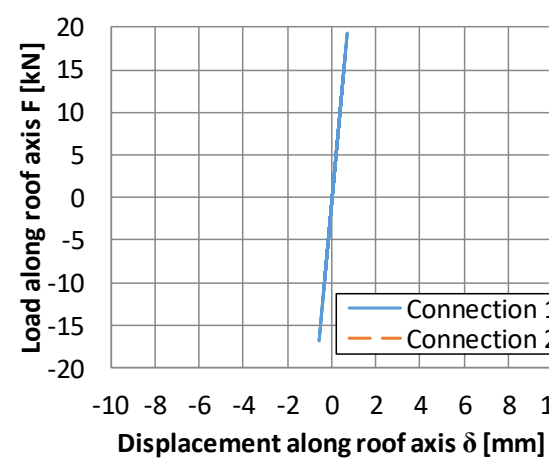

(f)

FIGURE 10. Analysis on bare frame with PGA = 0.70g: vibratory curves with (a) hot rolled angle, (b) cold formed angle, (c) dowel, and corresponding hysteresis of a couple of (d) hot rolled angle, (e) cold formed angle, (f) dowel roof-to-beam connections

In both cases, the maximum relative displacement is attained with the use of cold formed angles, which are more flexible. It can be noted from the hysteresis cycles of the connections that the angles were activated and acted in the plastic field, while the dowels remained in the elastic regime. The maximum load on the connections is comparable among the three solutions. Conversely, the maximum displacement demand for the connections is limited to about $4 \mathrm{~mm}$ for hot rolled angles, 6 $\mathrm{mm}$ for cold formed angles and $0.5 \mathrm{~mm}$ for dowels, which are all much lower values with respect to the displacement capacity of the connections. Finally, it can be observed that the hysteresis of the angles provided a contribution of energy dissipation which, even if modest with respect to the potential energy dissipation capacity of the columns, scarcely attained in these analyses, allowed to reduce the overall structural displacement.

The vibratory curves and the connection hysteresis cycles resulting from the analyses with restrained external frames performed at PGAs equal to $0.14 \mathrm{~g}$ and $0.525 \mathrm{~g}$ are reported in Figures 11 and 12 , respectively. In this case, the diaphragm is subjected to higher stress with respect to the bare frame 
case due to the large inhomogeneity of stiffness within the different lateral load resisting frames acting in parallel. A perfectly rigid diaphragm would lead to null displacement of the central frame, which is far from being obtained with any of the connections employed.

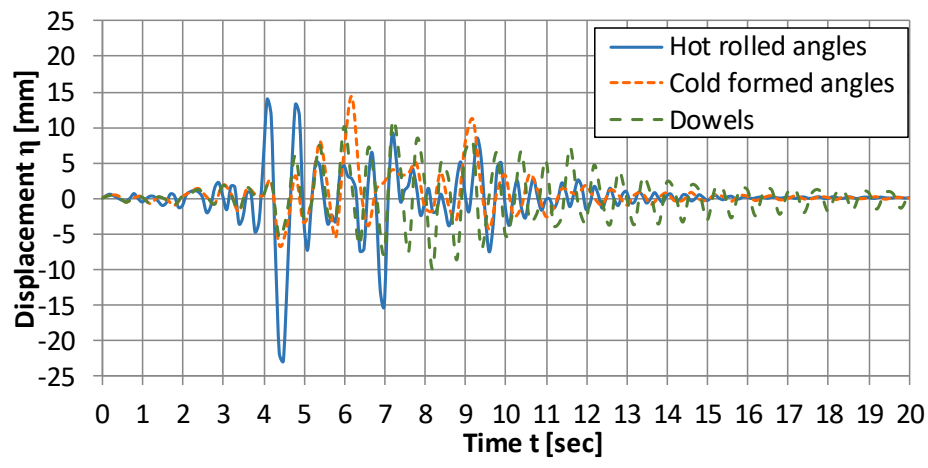

(a)

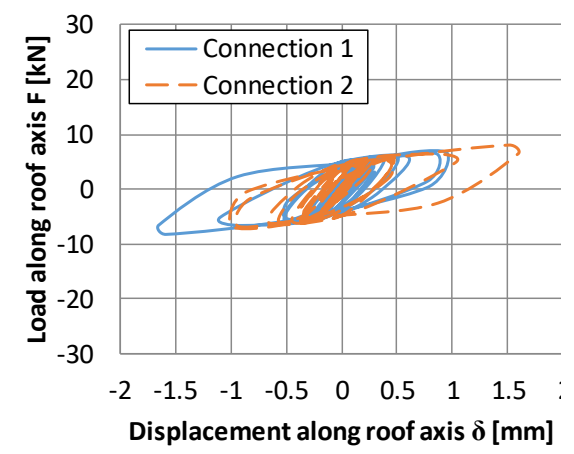

(b)

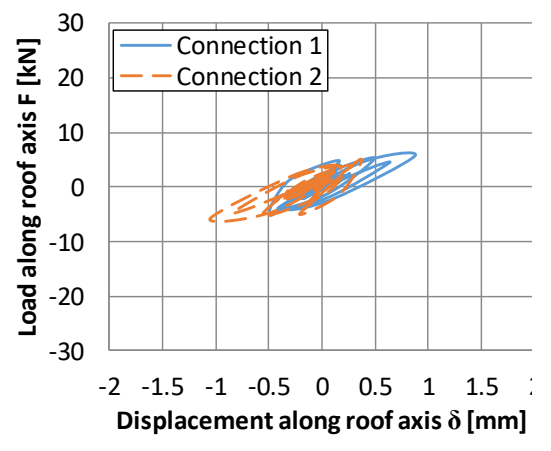

(c)

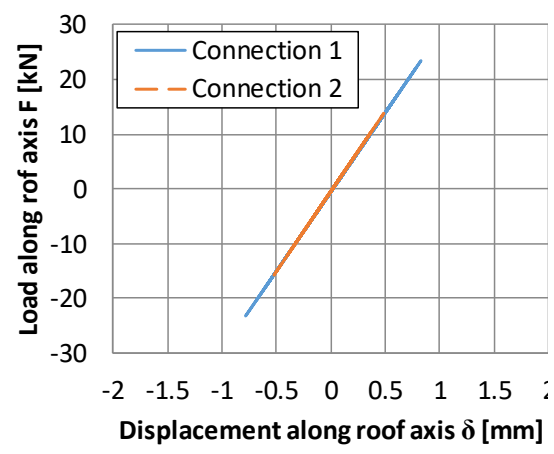

(d)

FIGURE 11. Analysis on braced frame with PGA $=0.14 \mathrm{~g}$ : (a) vibratory curves of the central frame with different deck connections, and hysteresis of a couple of (b) hot rolled angle, (c) cold formed angle, (d) dowel roof-to-beam connections

It can be observed that the predicted displacement of the central frame in the cases with and without cladding panels under the accelerogram scaled at $0.525 \mathrm{~g}$, is fundamentally the same, with a mere $20 \%$ difference. This indicates a poor collaboration of external and central frames. The deformation of the connections becomes relevant, up to more than $8 \mathrm{~mm}$, however still far from the capacity of the angles. Only the use of dowels can bring to a rigid diaphragm behaviour, with a relevant reduction of the top displacement of the central frame of about $80 \%$. This is due to the effective bracing action induced by the external frames and transmitted through the diaphragm. In the braced frame case, the dowels are subjected to a much higher action, which brings them to the yield limit. However, they barely entered the plastic range of displacement, still offering high deformation capacity. 


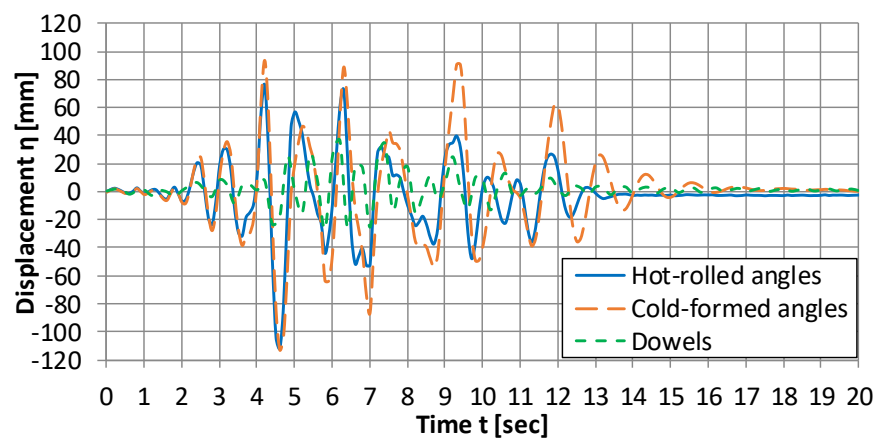

(a)

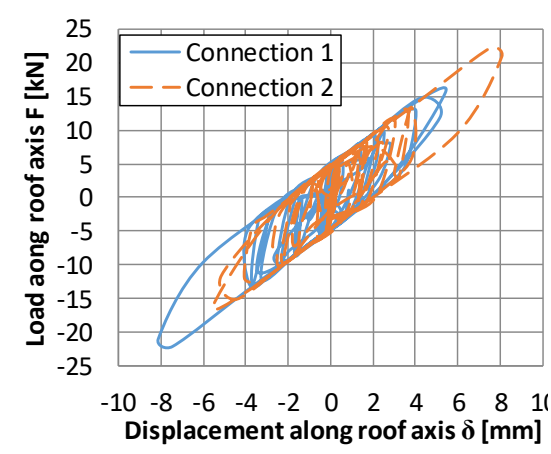

(b)

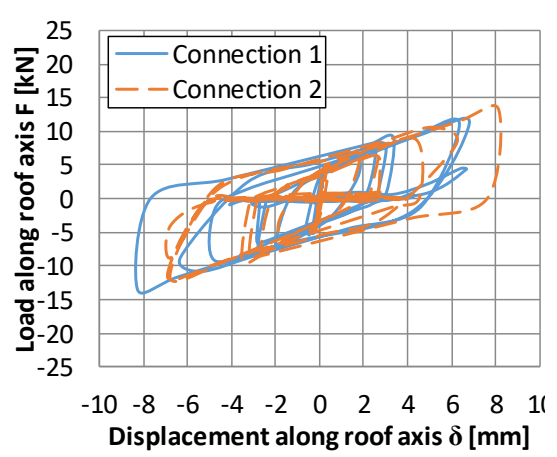

(c)

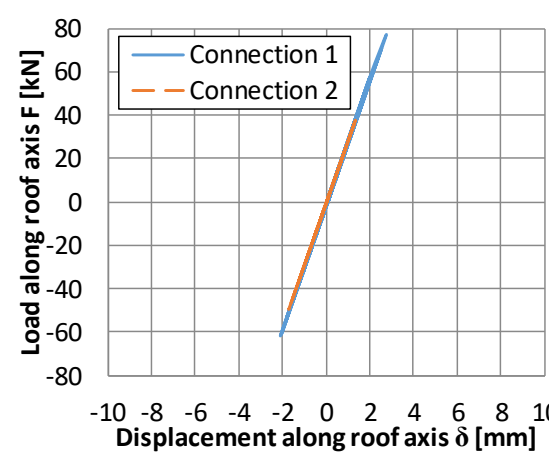

(d)

FIGURE 12. Analysis on braced frame with PGA = 0.525g: (a) vibratory curves of the central frame with different deck connections, and hysteresis of a couple of (b) hot rolled angle, (c) cold formed angle, (d) dowel roof-to-beam connections

\section{Non-linear dynamic analysis on a typical precast industrial building}

Additional analyses were performed on a precast structure more representative of the existing prefabricated building stock, since the test prototype was kept with limited dimensions due to laboratory constraints. The building completely described and analysed in [54] in a seismic design example where the ULS PGA was taken equal to $0.22 \mathrm{~g}$, was selected as a case study. The geometry of the building is shown in Figure 13a, and its elements are shown in Figure 13b. It is a regular building with rectangular plan of 50.15 by $41.75 \mathrm{~m}$ and $7.7 \mathrm{~m}$ of height. The columns have square section with $650 \mathrm{~mm}$ of side reinforced with 20 Ф20 rebars, corresponding to $1.49 \%$ of geometrical ratio. The transverse reinforcement consists of $\Phi 10$ stirrups spaced at $100 \mathrm{~mm}$ in the critical zone and $200 \mathrm{~mm}$ elsewhere. The roof is made with I beams spanning $10 \mathrm{~m}$ over 5 bays and with TT roof elements spanning 20.55 m over 2 bays. The concrete class is C45/55 and the steel grade is B450C. 


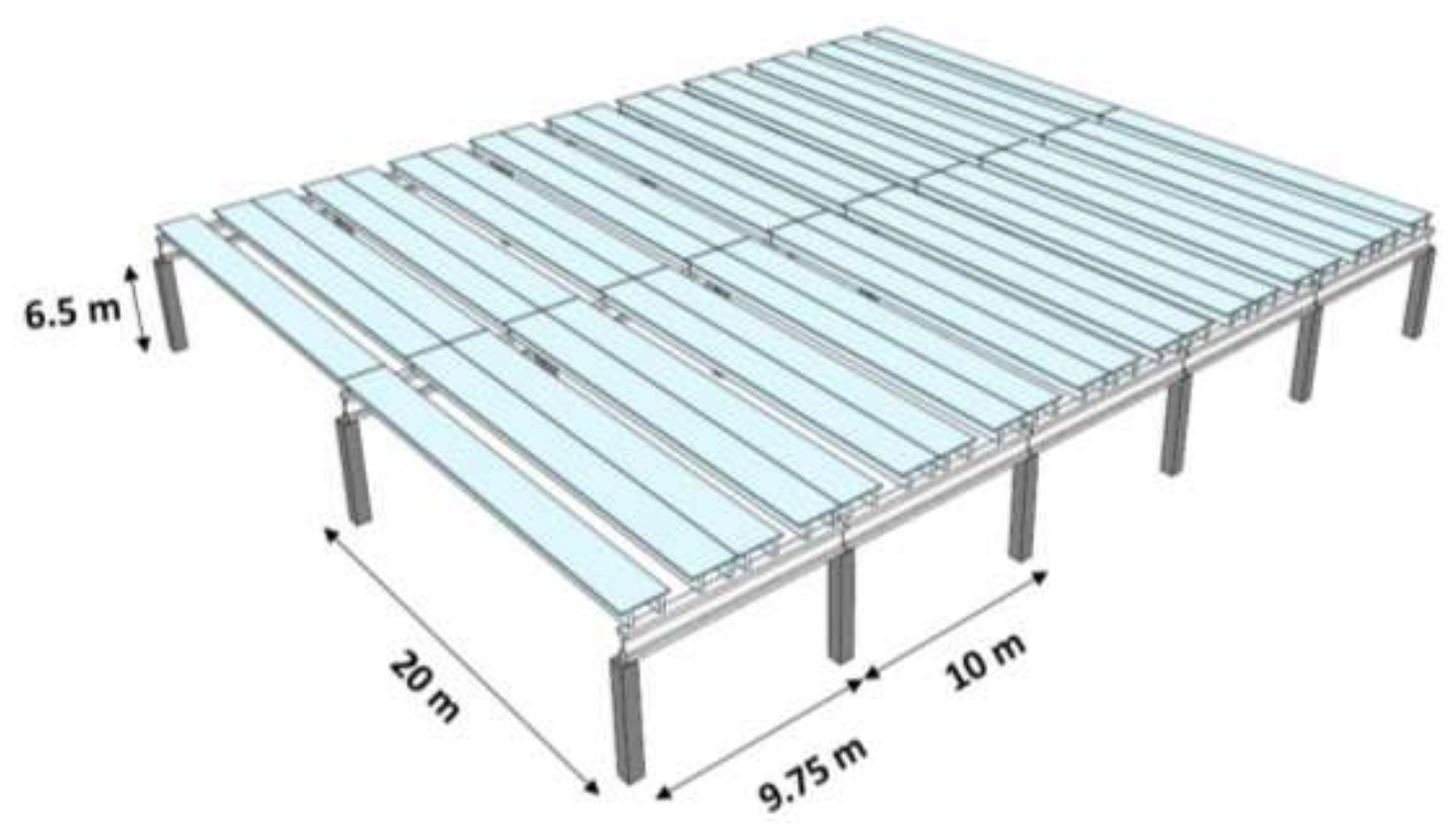

(a)
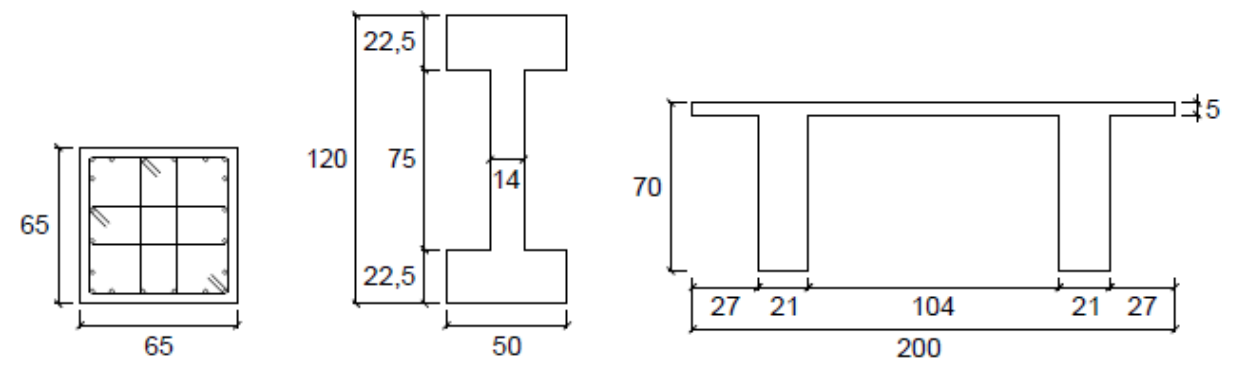

(b)

FIGURE 13. Industrial precast building: (a) structural layout, (b) structural elements [cm]

The results of the non-linear dynamic analyses on the bare frame model with different roof-to-beam connections are shown in Figures 14-15; the modified Tolmezzo accelerogram (Figure 6b) scaled at a PGA equal to $0.14 \mathrm{~g}$ and at the ULS PGA of $0.22 \mathrm{~g}$ has been employed. The diaphragm action is poor for all the considered connections. While out-of-phase vibration is reported when angle connections are employed. This tendency is less pronounced when dowels are employed. All the considered connections were subjected to a comparable displacement, to which higher load corresponds when dowels are employed. It can be noted from the hysteresis cycles of the connections that the angles were fully engaged in the plastic field, whereas the dowels did not overcome the elastic branch. 


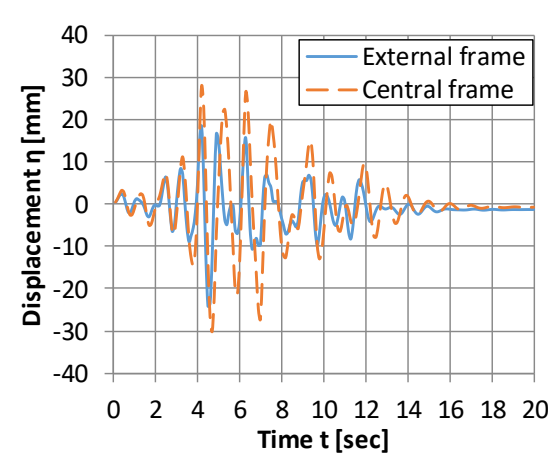

(a)

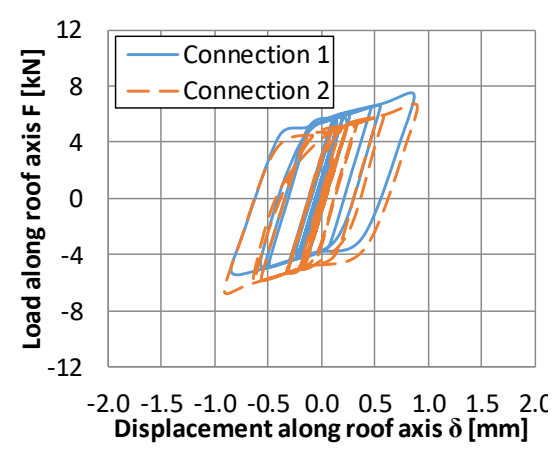

(d)

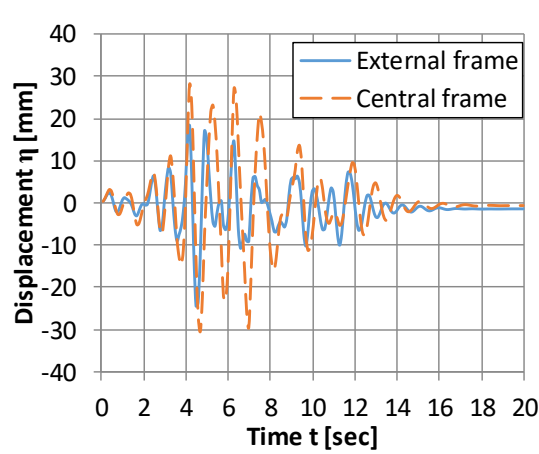

(b)

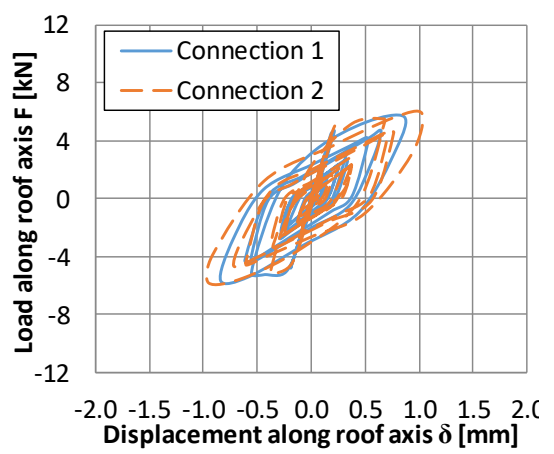

(e)

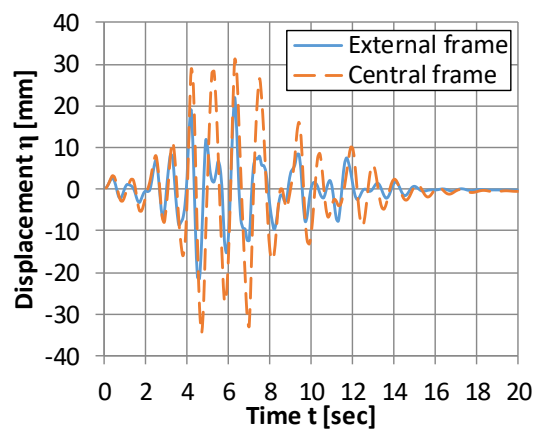

(c)

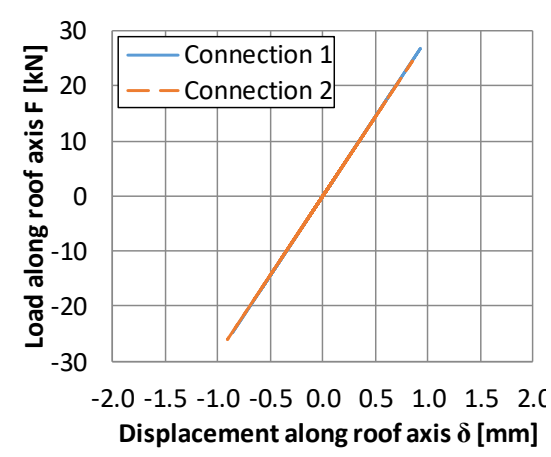

(f)

FIGURE 14. Analysis on bare frame with PGA $=0.14 \mathrm{~g}$ : vibratory curves with (a) hot rolled angle, (b) cold formed angle, (c) dowel, and corresponding hysteresis of a couple of (d) hot rolled angle, (e) cold formed angle, (f) dowel roof-to-beam connections 


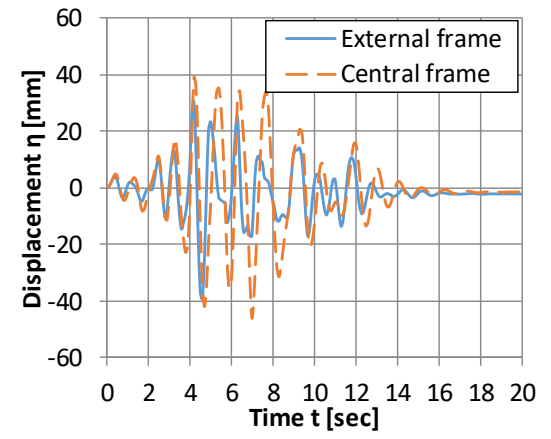

(a)

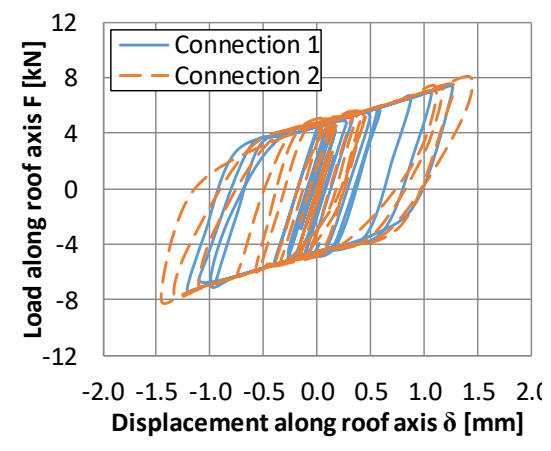

(d)

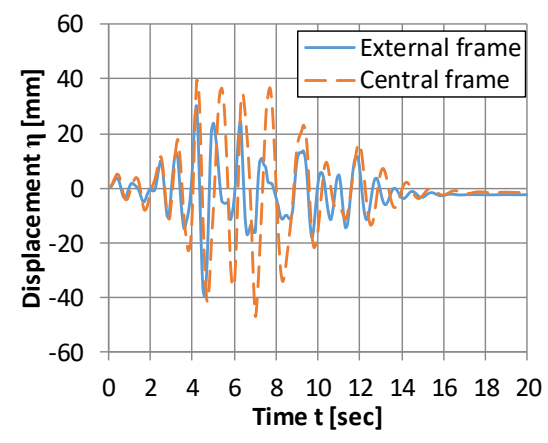

(b)

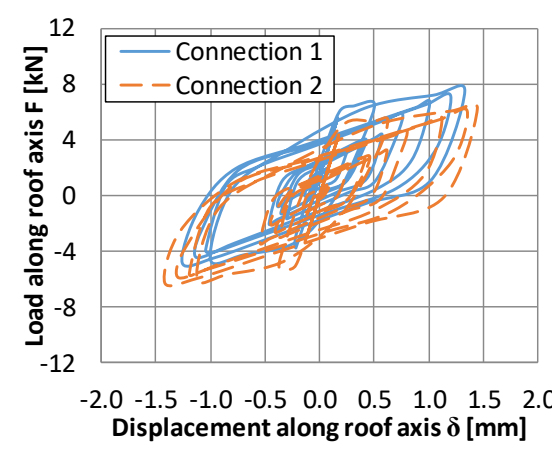

(e)

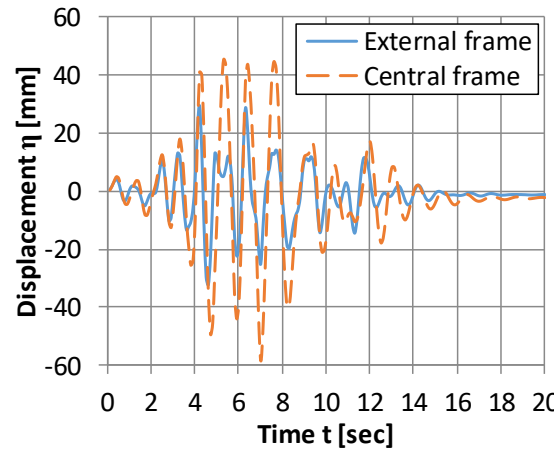

(c)

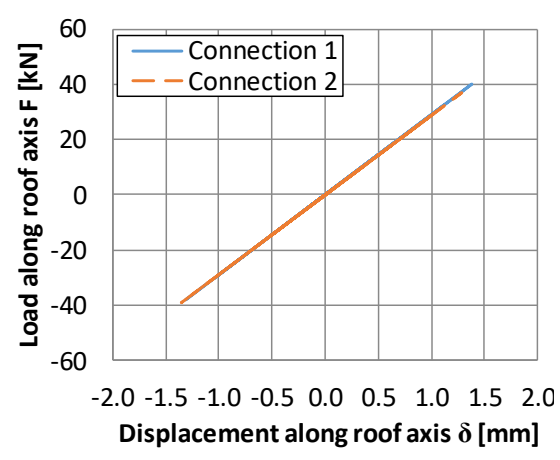

(f)

FIGURE 15. Analysis on bare frame with $\mathrm{PGA}=0.22 \mathrm{~g}$ : vibratory curves with (a) hot rolled angle, (b) cold formed angle, (c) dowel, and corresponding hysteresis of a couple of (d) hot rolled angle, (e) cold formed angle, (f) dowel roof-to-beam connections

The seismic performance of the externally braced industrial building, shown in Figure 16 under the accelerogram scaled at the ULS PGA of $0.22 \mathrm{~g}$, confirms that the maximum displacements of the structure and of the connections do not vary significantly with the type of roof-to-beam connection. However, to similar displacements corresponds higher stress for the dowels, even if still lower than the yielding limit. The diaphragm action is poor in all cases, since the central frame vibrates practically independently from the external ones, as it can be seen by comparing the vibratory curves of the bare frame and braced frame configurations. 


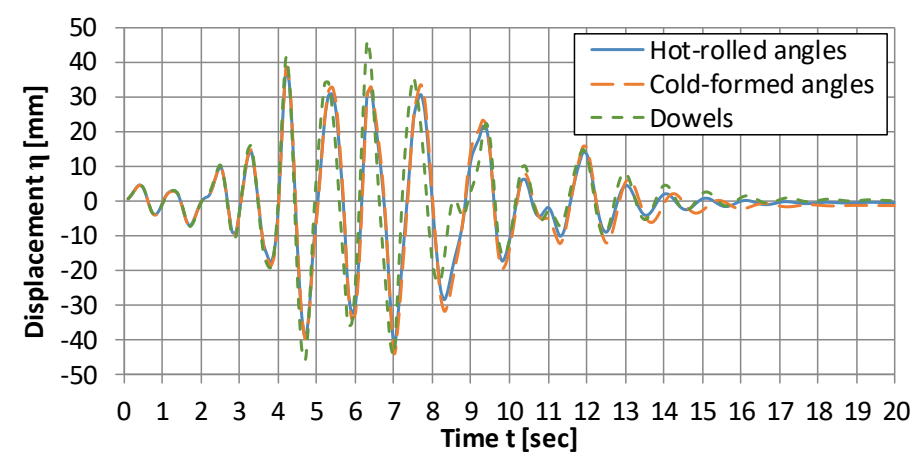

(a)

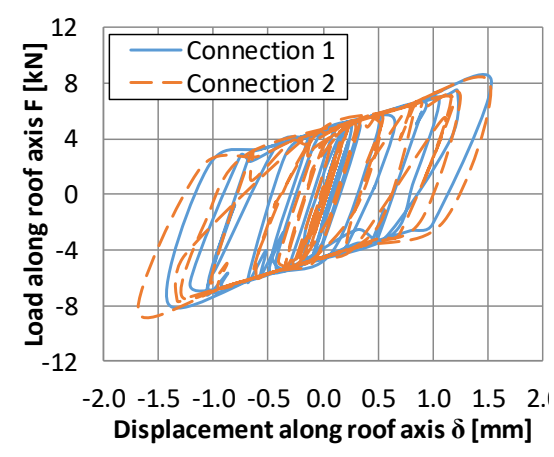

(b)

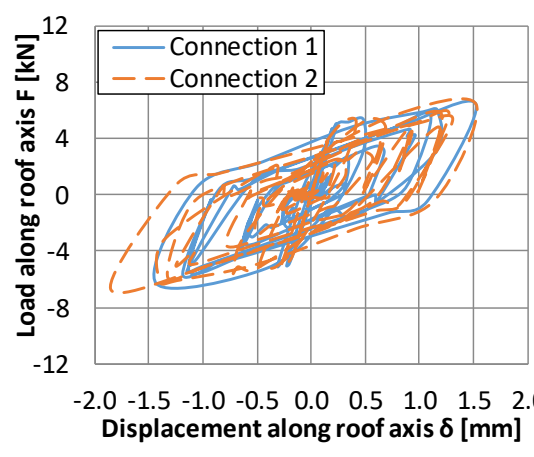

(c)

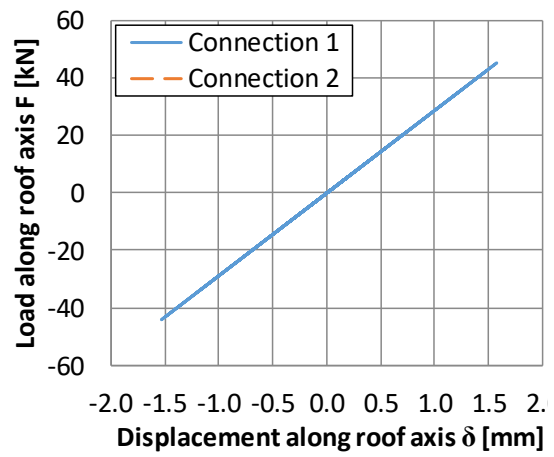

(d)

FIGURE 16. Analysis on braced frame with PGA $=0.22 \mathrm{~g}$ : (a) vibratory curves of the central frame with different deck connections, and hysteresis of a couple of (b) hot rolled angle, (c) cold formed angle, (d) dowel roof-to-beam connections

\section{Analytical interpretation}

An analytical model has been formulated with the aim to interpret the numerical results. This model might provide a simplified tool for the seismic proportioning of precast structures with non-rigid diaphragm and for the evaluation of the efficiency of the diaphragm and of the forces acting in the connections. The model is based on the definition of elastic springs: translation springs model the stiffness of the different frames of the lateral load resisting system, whereas rotation springs model the stiffness of the beam-to-column connections, based on the degree of restraint provided by two connections as spaced by the rib distance. The degrees of freedom of the model, which considers the floor/roof members as rigid bodies, are illustrated in Figure 17a. The translation and rotation springs are schematically represented in Figure 17b. If the conditions of structural regularity are fulfilled, as is typically required for the use of equivalent static force method for seismic design, the load indicated in Figure 17b can be used for the evaluation of the masses associated to the displacement degrees of 
freedom of the different frames. Distributed loads are associated to the distributed mass of added dead and live loads summed to the self-weight of floor/roof elements and the point loads are associated to the self-weight of the frames and eventually of the cladding panel row. It is worth remarking that the uniformly distributed load is truly representing the inertia forces only in the case of equal displacements of the frames (or rigid diaphragm). In this simplified model, it has been kept uniformly distributed also in the case of non-rigid diaphragm.

The stiffness $k_{i}$ of each translation spring is defined as the sum of the displacement stiffness $k_{i j}$ of each individual column $j$ on the $i$-th frame, as per Equation 01, where the formula is specified for cantilever-type columns having flexural stiffness $E I_{i j}$ and clear height $H_{j}$. Due to the intrinsic deformability of the cantilever-type static scheme, the second order correction factor $g_{j}$ is also introduced, as specified in Equation 01.

$$
k_{i}=\sum_{j} k_{i j}=3 \sum_{j} \frac{E I_{i j}}{H_{i j}{ }^{3}} g_{j}=\sum_{j} \frac{E I_{i j}}{H_{i j}{ }^{3}} \frac{\alpha_{i j}{ }^{3} H_{i j}{ }^{3}}{\tan \alpha_{i j} H_{i j}-\alpha_{i j} H_{i j}}
$$

where $\alpha_{i j}=\sqrt{ }\left(N_{i j} / E I_{i j}\right)$, being $N_{i j}$ the axial load of the column $j$ of the $i$-th frame. The flexural stiffness $E I_{p}$ of each equivalent beam on the $p$-th bay is calculated as the sum of the individual flexural stiffness of each of the $k$-th roof element, as per Equation 02.

$$
E I_{p}=\sum_{k} E I_{p k}
$$

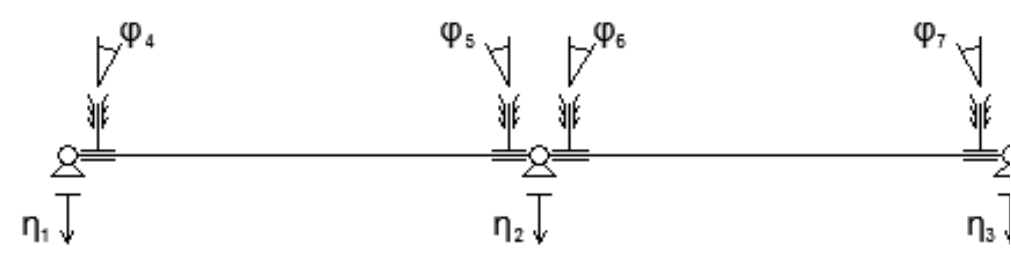

(a)

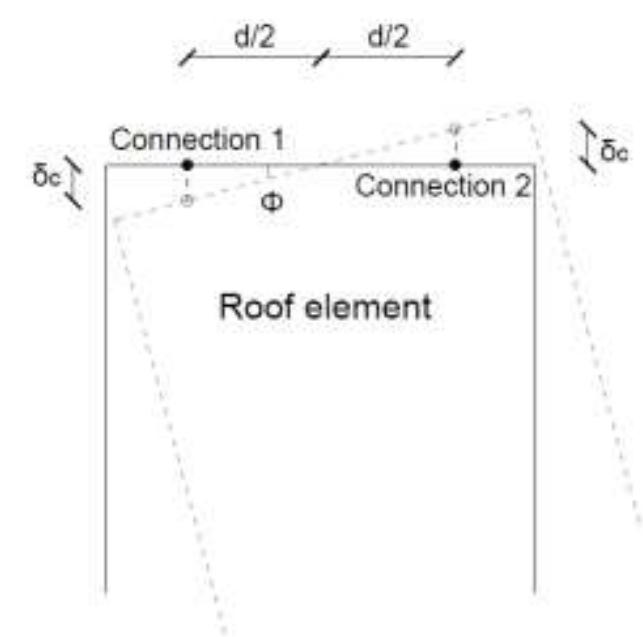

(b)

(c)

FIGURE 17. Simplified mechanical model: (a) degrees of freedom, (b) stiffness and mass distribution, (c) kinematics of the edge of a floor/roof element 
The rotation stiffness $\mu_{z}$ of each of the $z$-th rotational springs placed at the ends of the beams is calculated as the sum of the individual rotation stiffness of each of the $k$-th roof element, as per Equation 03, where $F_{c o n n}$ is the force on the connection, $k_{\text {conn }}$ the translation stiffness, $\delta$ the displacement of the floor-to-beam connection in the direction parallel to the floor axis and $d$ is the distance between the two connections on the same element (Figure 17c).

$$
\mu_{z}=\sum_{k} \mu_{z k}=\sum_{k} \frac{M_{z k}}{\varphi_{z k}}=\sum_{k} \frac{F_{c o n n, z k}}{\delta_{z k}} \frac{d_{z k}^{2}}{2}=\sum_{k} k_{c o n n, z k} \frac{d_{z k}^{2}}{2}
$$

After the solution of the problem, the distortion of the diaphragm can be evaluated, and an assessment of its rigidity can be performed. According to Eurocode 8 [07], a diaphragm is considered as effective if the displacements of its different parts differ by less than $10 \%$. With reference to the building shown in Figure 18, this rule can be expressed as per Equation 04.

$$
0.9 \leq \frac{\eta_{2}}{\eta_{1}} \leq 1.1
$$

This limitation is absolute and does not consider the effective length of the bays, leading to a difficult application to traditional precast structures, as it will be shown further on. Moreover, it does not consider the situation of a perfect bracing system inserted in one frame of the structure. For example, if considering the external frame of Figure 18 as perfectly braced, the ratio of Equation 04 diverges to infinite and it cannot fulfil the required condition even assuming a very large diaphragm stiffness. An alternative proposal is to consider the relative distortion of each bay, and to limit it to a threshold value (Equation 05), similarly to what is done when checking the deflection of a beam under gravity load for serviceability limit state.

$$
\Delta \eta=\left|\eta_{1}-\eta_{2}\right| \leq \frac{L}{500} \div \frac{L}{250}
$$

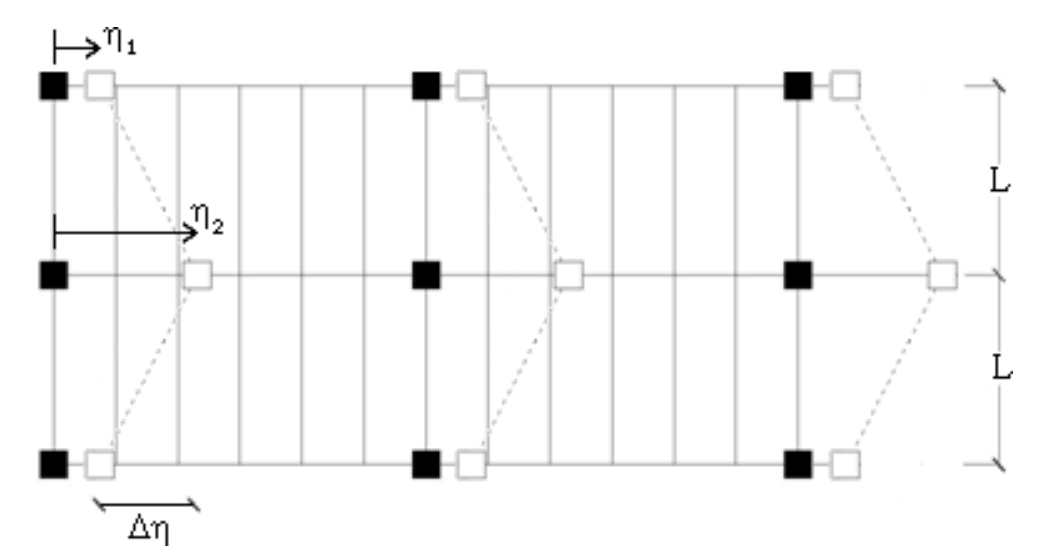

FIGURE 18. Definition of the quantities to be checked 
The results of the simplified static equivalent analytical procedure applied to all cases considered in the non-linear dynamic analysis carried out on the above-described test prototype and industrial building are reported in Table 1 and in Table 2, respectively. The results are compared with those obtained from the numerical analyses. The different connections have been modelled elastically, considering the elastic stiffness for the dowels and the post-activation stiffness for the angles. The force on the angles resulting from the procedure by multiplying the expected displacement by the stiffness has been increased by the activation load threshold, considered equal to $5 \mathrm{kN}$ (Equation 06). The stiffness values used are calibrated on the basis of the experimental values as described above in the simplified macro-models of the different connections.

$$
F_{\text {conn }}= \begin{cases}k_{\text {conn }} \cdot \delta_{\text {conn }} & \text { for dowels } \\ k_{\text {conn }} \cdot \delta_{\text {conn }}+5 k N & \text { for angles }\end{cases}
$$

The final force on the connections shall include the share perpendicular to the roof element axis, which is associated to the mass of the single element. The forces can usually be combined with a vectoral sum.

In terms of definition of rigid diaphragm, it can be noted that none of the cases considered, even at low PGA, is below the limit of $10 \%$ of displacement ratio $\eta_{2} / \eta_{1}$. The proposed evaluation criterion leads to more reasonable indications about the effectiveness of the diaphragm effect. For the test prototype, where the span of the roof elements is relatively short $(8 \mathrm{~m})$, the use of angle connections did not provide a strong diaphragm action in any of the cases investigated. In this case, the use of dowels brings to a much better performance of the diaphragm.

TABLE 1. Results of the simplified static analytical procedure compared with the numerical model (FEM): test prototype

\begin{tabular}{|c|c|c|c|c|c|c|c|c|c|c|c|c|c|}
\hline \multirow{2}{*}{$\begin{array}{c}\text { Connection } \\
\text { type }\end{array}$} & \multirow{2}{*}{$\begin{array}{c}\text { Structural } \\
\text { arrangement }\end{array}$} & \multirow{2}{*}{ PGA [g] } & \multicolumn{2}{|c|}{$\eta_{1}=\eta_{3}[\mathrm{~m}]$} & \multicolumn{2}{|c|}{$\eta_{2}[\mathrm{~m}]$} & \multirow{2}{*}{$\eta_{2} / \eta_{1}$} & \multirow{2}{*}{$\Delta n[\mathrm{~m}]$} & \multirow{2}{*}{$L / \Delta \eta$} & \multicolumn{2}{|c|}{$\mathrm{F}_{\text {conn } / /}[\mathrm{kN}]$} & \multicolumn{2}{|c|}{$\delta_{\max }[\mathrm{mm}]$} \\
\hline & & & Analytical & FEM & Analytical & FEM & & & & Analytical & FEM & Analytical & FEM \\
\hline \multirow{4}{*}{$\begin{array}{c}\text { Hot rolled } \\
\text { angles }\end{array}$} & \multirow{2}{*}{ Bare frame } & 0.525 & 0.063 & 0.106 & 0.110 & 0.144 & 1.75 & 0.048 & 166 & 12.90 & 13.90 & 3.36 & 3.97 \\
\hline & & 0.7 & 0.083 & 0.119 & 0.147 & 0.176 & 1.77 & 0.064 & 125 & 15.54 & 15.96 & 4.49 & 4.88 \\
\hline & \multirow{2}{*}{ Braced frame } & 0.14 & 0.000 & 0.000 & 0.030 & 0.023 & $\infty$ & 0.030 & 266 & 9.91 & 8.27 & 2.08 & 1.66 \\
\hline & & 0.525 & 0.000 & 0.000 & 0.112 & 0.112 & $\infty$ & 0.112 & 71 & 23.40 & 22.12 & 7.80 & 8.11 \\
\hline \multirow{4}{*}{$\begin{array}{l}\text { Cold formed } \\
\text { angles }\end{array}$} & \multirow{2}{*}{ Bare frame } & 0.525 & 0.061 & 0.097 & 0.114 & 0.137 & 1.87 & 0.053 & 150 & 8.92 & 10.29 & 3.76 & 5.67 \\
\hline & & 0.7 & 0.081 & 0.137 & 0.152 & 0.221 & 1.88 & 0.071 & 112 & 10.23 & 13.72 & 5.01 & 9.18 \\
\hline & \multirow{2}{*}{ Braced frame } & 0.14 & 0.000 & 0.000 & 0.032 & 0.014 & $\infty$ & 0.032 & 250 & 7.36 & 5.71 & 2.25 & 0.87 \\
\hline & & 0.525 & 0.000 & 0.000 & 0.121 & 0.113 & $\infty$ & 0.120 & 66 & 13.83 & 13.36 & 8.44 & 8.27 \\
\hline \multirow{4}{*}{ Dowels } & \multirow{2}{*}{ Bare frame } & 0.525 & 0.073 & 0.190 & 0.089 & 0.196 & 1.22 & 0.015 & 533 & 31.08 & 17.22 & 1.10 & 0.59 \\
\hline & & 0.7 & 0.098 & 0.231 & 0.118 & 0.236 & 1.2 & 0.021 & 380 & 41.44 & 16.78 & 1.46 & 0.58 \\
\hline & \multirow{2}{*}{ Braced frame } & 0.14 & 0.000 & 0.000 & 0.012 & 0.011 & $\infty$ & 0.012 & 666 & 23.93 & 22.60 & 0.83 & 0.79 \\
\hline & & 0.525 & 0.000 & 0.000 & 0.045 & 0.036 & $\infty$ & 0.045 & 177 & 89.72 & 72.13 & 3.12 & 2.57 \\
\hline
\end{tabular}


TABLE 2. Results of the simplified static analytical procedure compared with the numerical model (FEM): industrial building

\begin{tabular}{|c|c|c|c|c|c|c|c|c|c|c|c|c|c|}
\hline \multirow{2}{*}{$\begin{array}{l}\text { Connection } \\
\text { type }\end{array}$} & \multirow{2}{*}{$\begin{array}{c}\text { Structural } \\
\text { arrangement }\end{array}$} & \multirow{2}{*}{ PGA [g] } & \multicolumn{2}{|c|}{$\eta_{1}=\eta_{3}[m]$} & \multicolumn{2}{|c|}{$\eta_{2}[\mathrm{~m}]$} & \multirow{2}{*}{$\eta_{2} / \eta_{1}$} & \multirow{2}{*}{$\Delta \eta[\mathrm{m}]$} & \multirow{2}{*}{$L / \Delta \eta$} & \multicolumn{2}{|c|}{$\mathrm{F}_{\text {conn } / /}[\mathrm{kN}]$} & \multicolumn{2}{|c|}{$\delta_{\max }[\mathrm{mm}]$} \\
\hline & & & Analytical & FEM & Analytical & FEM & & & & Analytical & FEM & Analytical & FEM \\
\hline \multirow{3}{*}{$\begin{array}{l}\text { Hot rolled } \\
\text { angles }\end{array}$} & \multirow{2}{*}{ Bare frame } & 0.14 & 0.024 & 0.024 & 0.034 & 0.030 & 1.42 & 0.010 & 2055 & 5.70 & 7.00 & 0.37 & 0.74 \\
\hline & & 0.22 & 0.038 & 0.039 & 0.053 & 0.046 & 1.39 & 0.015 & 1370 & 6.10 & 8.14 & 0.58 & 1.40 \\
\hline & Braced frame & 0.22 & 0.000 & 0.000 & 0.081 & 0.042 & $\infty$ & 0.081 & 253 & 10.79 & 8.53 & 2.62 & 1.69 \\
\hline \multirow{3}{*}{$\begin{array}{l}\text { Cold formed } \\
\text { angles }\end{array}$} & \multirow{2}{*}{ Bare frame } & 0.14 & 0.024 & 0.025 & 0.034 & 0.031 & 1.41 & 0.010 & 2055 & 5.31 & 5.78 & 0.37 & 0.96 \\
\hline & & 0.22 & 0.038 & 0.039 & 0.053 & 0.047 & 1.39 & 0.015 & 1370 & 5.49 & 6.72 & 0.58 & 1.45 \\
\hline & Braced frame & 0.22 & 0.000 & 0.000 & 0.082 & 0.044 & $\infty$ & 0.082 & 250 & 7.59 & 6.62 & 2.64 & 1.74 \\
\hline \multirow{3}{*}{ Dowels } & \multirow{2}{*}{ Bare frame } & 0.14 & 0.025 & 0.021 & 0.033 & 0.034 & 1.32 & 0.008 & 2568 & 6.88 & 27.84 & 0.31 & 0.94 \\
\hline & & 0.22 & 0.039 & 0.032 & 0.051 & 0.058 & 1.31 & 0.012 & 1712 & 10.81 & 40.40 & 0.48 & 1.41 \\
\hline & Braced frame & 0.22 & 0.000 & 0.000 & 0.070 & 0.046 & $\infty$ & 0.070 & 293 & 60.93 & 44.91 & 2.25 & 1.50 \\
\hline
\end{tabular}

Conversely, for the industrial building, where the span length of the roof elements is $20.55 \mathrm{~m}$, the use of both angle or dowel connections provides a strong diaphragm action in all the investigated cases with bare frame structures and a good diaphragm action in the cases with braced frame structures. However, the use of dowels brings to a better performance of the diaphragm.

It is worth remarking that the effectiveness of the diaphragm decreases with increasing PGAs in both cases.

It can be furthermore noted that in some cases the estimation of the force acting on the connections provides a poor matching with the numerical results and a relevant underestimation when dowels are employed in the industrial building. This happens when the dynamic behaviour of the structure is affected by higher modes associated to the vibration of the deck. In particular, a clear example is given in Figure 14c, where it can be noted that in between 5 and 6 seconds of motion, the different frames behave in counter-phase. This induces additional distortions in the deck which shall be taken into account for the determination of the force acting on the connections. For all these cases where higher modes of the deck affect the seismic response, the model can be adapted to be solved with modal analysis.

Table 3 shows the results of the application of modal analysis to those cases in which the estimation of the force on the connection was poor, all related to the industrial building only. The estimation of the force carried out by using the rule of the Square Root of the Sum of the Squares (SRSS) is proved to be much more reliable. 
TABLE 3. Results of the simplified modal analytical procedure compared with the numerical model (FEM): industrial building

\begin{tabular}{|c|c|c|c|c|c|c|c|c|c|c|c|c|c|}
\hline \multirow{2}{*}{$\begin{array}{l}\text { Connection } \\
\text { type }\end{array}$} & \multirow{2}{*}{$\begin{array}{c}\text { Structural } \\
\text { arrangement }\end{array}$} & \multirow{2}{*}{ PGA [g] } & \multicolumn{2}{|c|}{$\eta_{1}=\eta_{3}[\mathrm{~m}]$} & \multicolumn{2}{|c|}{$\eta_{2}[\mathrm{~m}]$} & \multirow{2}{*}{$\eta_{2} / \eta_{1}$} & \multirow{2}{*}{$\Delta \eta[\mathrm{m}]$} & \multirow{2}{*}{$\mathrm{L} / \Delta \eta$} & \multicolumn{2}{|c|}{$\mathrm{F}_{\mathrm{conn} / /}[\mathrm{kN}]$} & \multicolumn{2}{|c|}{$\delta_{\max }[\mathrm{mm}]$} \\
\hline & & & Analytical & FEM & Analytical & FEM & & & & Analytical & FEM & Analytical & FEM \\
\hline \multirow{2}{*}{$\begin{array}{l}\text { Hot rolled } \\
\text { angles }\end{array}$} & \multirow{2}{*}{ Bare frame } & 0.14 & 0.019 & 0.024 & 0.033 & 0.030 & 1.74 & 0.014 & 1468 & 7.68 & 7.00 & 0.43 & 0.74 \\
\hline & & 0.22 & 0.029 & 0.039 & 0.052 & 0.046 & 1.79 & 0.023 & 893 & 9.22 & 8.14 & 0.70 & 1.40 \\
\hline \multirow{2}{*}{$\begin{array}{l}\text { Cold formed } \\
\text { angles }\end{array}$} & \multirow{2}{*}{ Bare frame } & 0.14 & 0.019 & 0.025 & 0.033 & 0.031 & 1.74 & 0.014 & 1468 & 6.19 & 5.78 & 0.43 & 0.96 \\
\hline & & 0.22 & 0.029 & 0.039 & 0.052 & 0.047 & 1.79 & 0.023 & 893 & 6.87 & 6.72 & 0.70 & 1.45 \\
\hline \multirow{2}{*}{ Dowels } & \multirow{2}{*}{ Bare frame } & 0.14 & 0.015 & 0.021 & 0.033 & 0.034 & 2.20 & 0.018 & 1142 & 23.09 & 27.84 & 0.55 & 0.94 \\
\hline & & 0.22 & 0.020 & 0.032 & 0.052 & 0.058 & 2.60 & 0.032 & 642 & 33.08 & 40.40 & 0.97 & 1.41 \\
\hline
\end{tabular}

\section{Parametric analysis}

The simplified method illustrated in the previous section has been used to perform a parametric analysis on the industrial building, which is more representative of the existing building stock, to investigate the role of the following parameters on the effectiveness of the diaphragm: (a) translation stiffness of floor-to-beam connections, (b) out-of-plane flexural stiffness of floor/roof elements, (c) uniformity, defined as the ratio of the natural vibration modes $T_{1}$ and $T_{2}$ associated to the external and internal frames, respectively, and (d) PGA.

Figure 19 shows the influence of the stiffness of the connection $k_{c o n n}$ on the seismic performance of the bare frame structure. The range of order of magnitude of $k_{\text {conn }}$ for the connections investigated in the present paper $(1-30 \mathrm{kN} / \mathrm{mm})$ falls well before the asymptotic values of the curves, which indicate a perfect diaphragm action.

The diagrams concerning the influence of the out-of-plane stiffness $E I$ of the roof elements on the seismic performance of the bare frame are shown in Figure 20. The straight lines obtained for angle bracket connections indicate that this parameter does not influence at all the seismic performance of the building. Only in the case of dowel connections, the curves tend to bend for low values of stiffness (the stiffness of the TT elements investigated in the present papers is of the order of magnitude of $10^{11} \mathrm{Nm}^{2}$ ), but still the influence is very limited. 


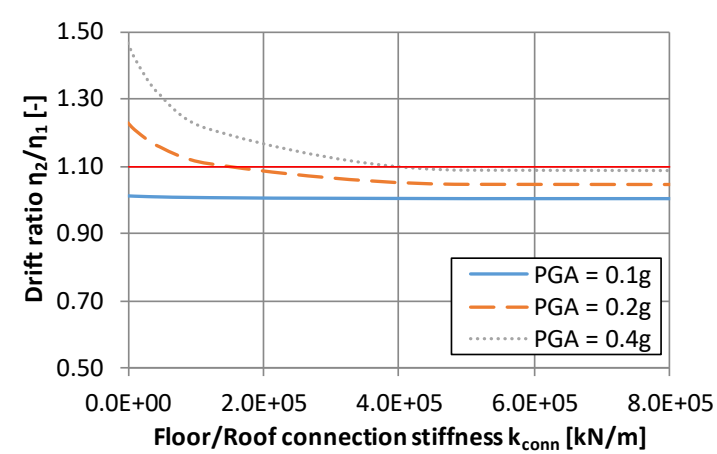

(a)

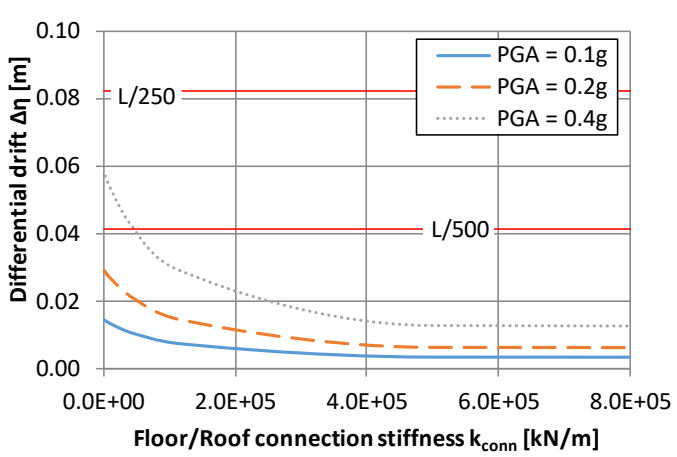

(b)

FIGURE 19. Influence of $k_{c o n n}$ on (a) $\eta_{2} / \eta_{1}$ and (b) $\Delta \eta$

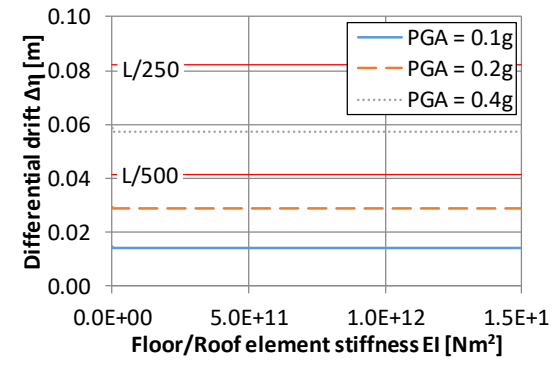

(a)

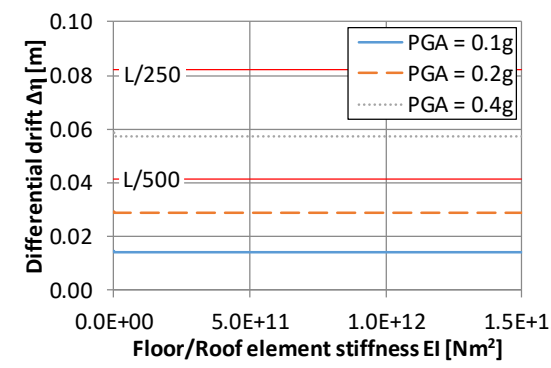

(d)

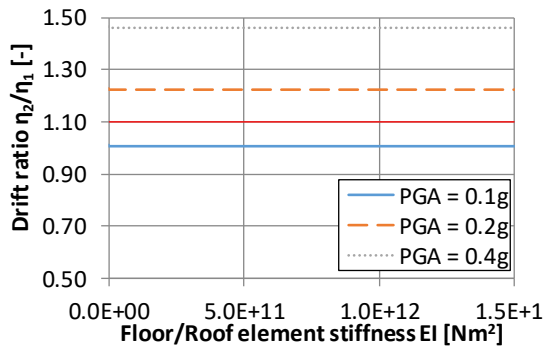

(b)

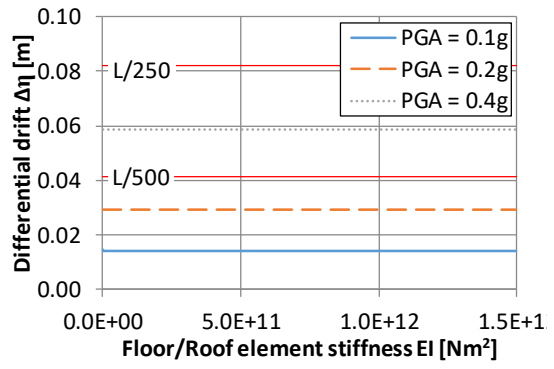

(e)

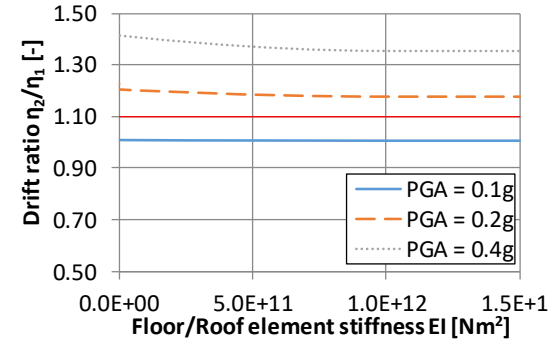

(c)

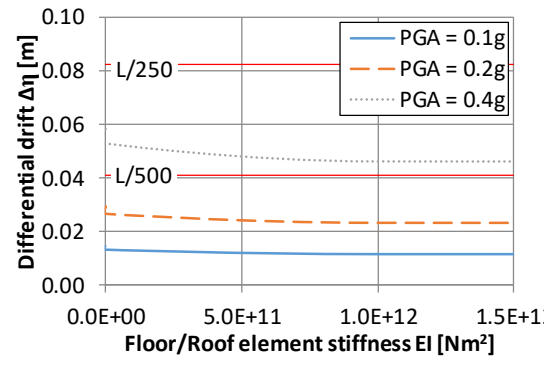

(f)

FIGURE 20. Influence of $E I_{k}$ on $\eta_{2} / \eta_{1}$ - (a) hot-rolled angles, (b) cold-formed angles, (c) dowels and on $\Delta \eta$ - (d) hot-rolled angles, (e) cold-formed angles, (f) dowels

The dynamic uniformity of the frames is a main parameter for the determination of the performance of the diaphragm. As shown in Figure 21, for ratios between the fundamental periods of central and external frames other than one, the drift ratio function forms a cusp. The stiffer the connection, the wider is the cusp.

The level of PGA results into practically negligible differences among the curves. It can be noticed that the $10 \%$ requirement would be fulfilled only for very small variations of the period ratio. A much wider range of fulfilment is found when looking at the differential drift of the frames, with functions 
forming a cusp for values lower than one and asymptotic curves for values higher than one. The level of PGA determines a remarkable pinching of the curves, and a stricter fulfilment of the limitations. Concerning the displacement demand on the connection, it can be seen from the diagrams of Figure 22 that they depend almost linearly on the level of excitation, with steep curves for angles and much softer curves for dowels. In all the cases considered in the present paper, the demand of displacement in the direction of the roof axis was kept much lower than their capacity, which could be set to a functional limit of about $25 \mathrm{~mm}$ for both angles and dowels.

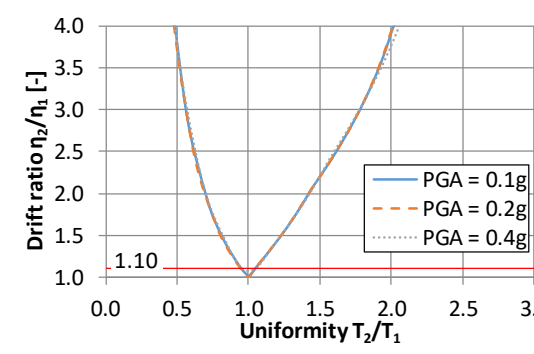

(a)

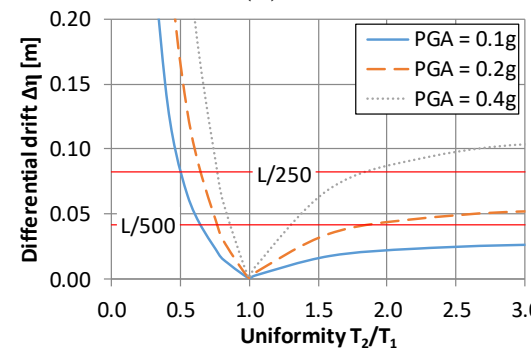

(d)

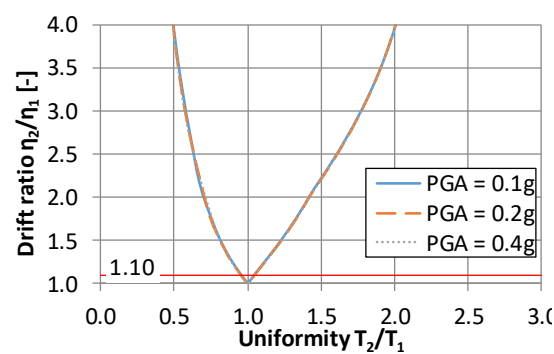

(b)

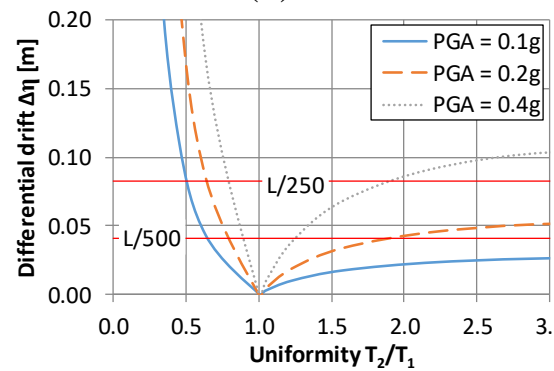

(e)

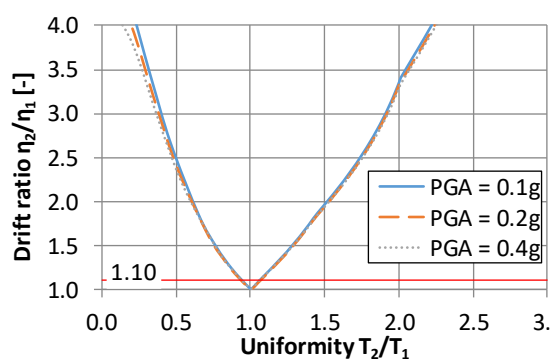

(c)

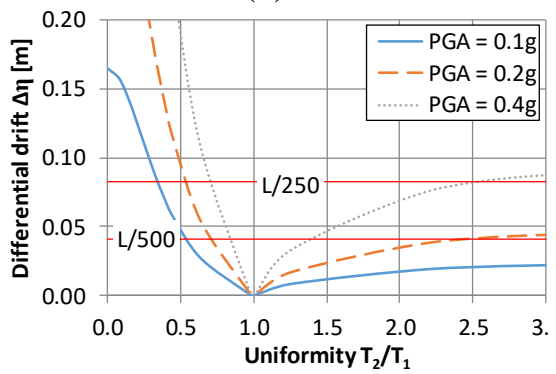

(f)

FIGURE 21. Influence of $T_{2} / T_{1}$ on $\eta_{2} / \eta_{1}$ - (a) hot-rolled angles, (b) cold-formed angles, (c) dowels and on $\Delta \eta$ - (d) hot-rolled angles, (e) cold-formed angles, (f) dowels

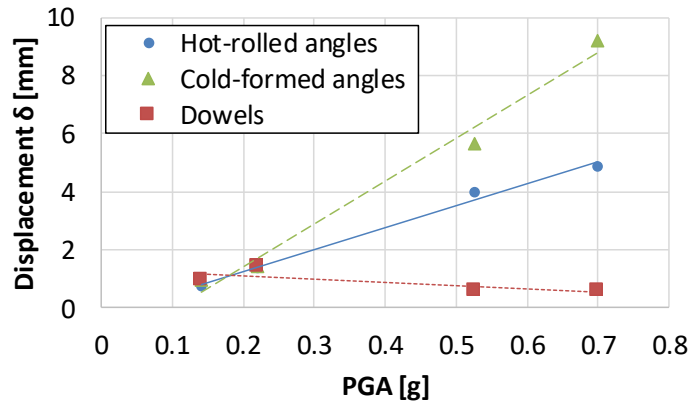

(a)

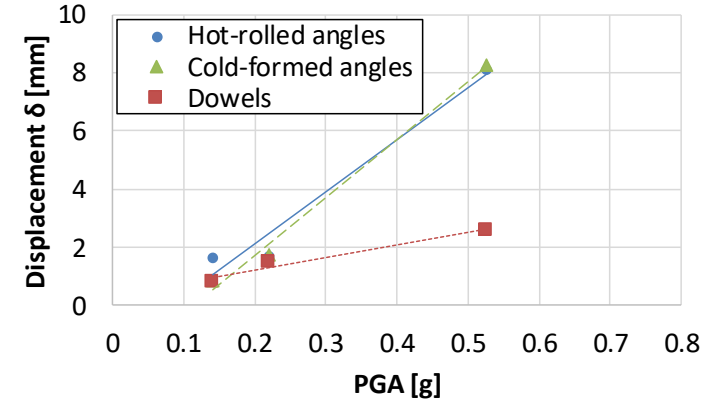

(b)

FIGURE 22. Displacement demand on the floor-to-beam connections (results from numerical analyses): (a) bare frames, (b) braced frames 


\section{Conclusions}

In this paper, the diaphragm effect of precast dry-assembled buildings under seismic action in the direction orthogonal to the roof elements has been investigated. Simplified load-displacement macromodels for the structural behaviour of hot-rolled angle brackets, cold-formed angle brackets and dowel roof-to-beam connections in the direction of the roof elements are proposed based on experimental evidence.

Dynamic non-linear analyses have been carried out on a finite element model whose validity and limits have been shown through the comparison against the results of a full-scale prototype of dryassembled precast industrial buildings tested within the framework of the Precast Structures EC8 research project. The results of analyses carried out on the test prototype buildings with different roofto-beam connections have shown that steel angle connections do not provide enough stiffness to the roof deck so to allow it to be considered as a rigid diaphragm. Dowel connections, which are provided with a higher stiffness, made effectively collaborate the different frames acting in parallel. These results have also been confirmed by the analyses carried out on the prototype supposed perfectly braced at the external frames, for instance by an integrated connection system of the cladding panels. When angle connections are employed, the central frame practically vibrates independently from the external ones. Conversely, a remarkable reduction of the maximum drift occurred with the use of dowels. However, this behaviour has not been confirmed when analysing an industrial structure with spans of the roof elements of about $20 \mathrm{~m}$, about three times longer than the test prototype ones, which better reflects the existing precast building stock. For this structure, none of the considered connections provides a rigid diaphragm behaviour.

It is to be pointed out that a non-rigid diaphragm behaviour does not automatically mean a bad seismic performance of the structure, as shown by the experimentation and the analyses. However, this shall be taken into account in the design by properly modelling the deck and its connections.

A simplified analytical procedure for the seismic design of precast structures with non-rigid diaphragms has been proposed and checked against the numerical results. The comparison with the numerical results shows that the application of the procedure with equivalent static actions catches the order of magnitude of the displacements of structure and connections, and the relative actions, given that the deck vibrates predominantly according to the first mode only. When this condition is not fulfilled, the equivalent force method provides wrong estimations of the displacement demand at the connection level, which are more accurately caught through modal dynamic analysis and are enlarged due to out-of-phase distortions of the deck. 
A parametric analysis performed with the analytical procedure highlighted that the level of PGA and the stiffness of the roof-to-beam connections play an important role on the diaphragm effectiveness. Conversely, the out-of-plane stiffness of the roof elements plays a negligible role, given that multiple ribbed elements are used. Even in the cases where the diaphragm action was effective, it could have not been considered rigid according to the rule of Eurocode 8 prescribing a differential displacement lower than $10 \%$, which proves to be too strict for precast buildings with usual large spans. A different approach based on the limitation of the differential drift has been proposed.

It has finally to be pointed out that a poor diaphragm effectiveness of the dry-assembled precast deck did not correspond in any of the analysed cases to a bad seismic performance of the deck, since the displacement demand of the roof-to-beam connections has been in all cases much lower than their capacity.

Acknowledgements Giulia Mariani Orlandi and Alessandro Rocci are gratefully acknowledged for their collaboration. The full-scale prototype experimentation shown in the paper was performed at the ELSA laboratory of the Joint Research Centre in Ispra (Italy) within the framework of the Growth research project with the acronym Precast Structures EC8 (grant agreement No. G6RD-CT-200270002). The experimental tests of roof-to-beam elements have been carried out in the framework of the Safecast project (FP7-SME-2007-2; grant agreement No. 218417/2009).

\section{References}

[01] Kunnath SK, Panahshahi N, Reinhorn AM. Seismic response of RC buildings with inelastic floor diaphragms. ASCE Journal of Structural Engineering 1991; 117(4): 1218-1237.

[02] Saffarini HS, Qudaimat MM. In-plane floor deformations in RC structures. ASCE Journal of Structural Engineering 1992; 118: 3089-3102.

[03]Dolce M, Lorusso VD, Masi A. Seismic response of building structures with flexible inelastic diaphragm. The Structural Design of Tall Buildings 1994, ASCE; 3: 87-106.

[04] Tena-Colunga A, Abrams PA. Seismic behaviour of structures with flexible diaphragms. ASCE Journal of Structural Engineering 1996; 122(4): 439-445.

[05] Ju SH, Lin MC. Comparison of building analyses assuming rigid or flexible floors. ASCE Journal of Structural Engineering 1999; 125: 25-39.

[06]Bull DK. Understanding the complexities of designing diaphragms in buildings for earthquakes. Bulletin of the New Zealand Society for Earthquake Engineering 2004; 37(2): 70-88. 
[07]CEN-EN 1998-1:2004. Eurocode 8: Design of structures for earthquake resistance - Part 1 General rules, seismic actions and rules for buildings. European Committee for Standardization 2004, Brussels, Belgium.

[08]ASCE/SEI 7-10. Minimum design loads for buildings and other structures: second printing. American Society of Civil Engineers/Structural Engineering Institute 2010, Reston, VA, USA.

[09]Clough DP. Consideration in the design and construction of precast concrete diaphragms for earthquake loads PCI Journal 1982; 3-4: 78-93.

[10]Fleischman RB, Sause R, Pessiki S, Rhodes AB. Seismic behavior of precast parking structure diaphragms. PCI Journal 1998; 43(1): 38-53.

[11]Fleischman RB, Farrow KT. Dynamic response of perimeter lateral-system structures with flexible diaphragms. Earthquake Engineering and Structural Dynamics 2001; 30(5): 745-763.

[12]Fleischman RB, Farrow KT, Eastman K. Seismic performance of perimeter lateral-system structures with highly flexible diaphragms. Earthquake Spectra 2002; 18(2): 251-286.

[13]Lee HJ, Kuchma DA. Seismic response of parking structures with precast concrete diaphragms. PCI Journal 2008, 53(2); 71-94.

[14]Fleischman RB, Farrow KT. Seismic design recommendations for precast concrete diaphragms in long floor span constructions. PCI Journal 2003;11-12: 46-62.

[15]Fleischman RB, Naito C, Restrepo J, Sause R, Ghosh SK. Seismic Design Methodology for Precast Concrete Diaphragms, Part 1: Design Framework. PCI Journal 2005; 9-10: 68-83.

[16]Fleischman RB, Ghosh SK, Naito C, Wan G, Restrepo J, Schoettler M, Sause R, Cao L. Seismic Design Methodology for Precast Concrete Diaphragms, Part 2: Research program. PCI Journal 2005; 11-12: 2-19.

[17] Torquati M, Belleri A, Riva P. Progettazione degli impalcati prefabbricati per il trasferimento delle forze orizzontali. Industrie manufatti cementizi 2012, 23: 20-29 (in Italian).

[18] Vides R, Pampanin S. Towards a performance-based design of precast concrete diaphragms using jointed dissipative connectors: concept and feasibility study. NZSEE Conference 2015, Rotorua, New Zealand, Paper O-45.

[19] Naito C, Cao L, Wesley P. Precast concrete double-tee connections, part 1: tension behaviour. PCI Journal 2009; Winter: 49-66.

[20] Naito C, Cao L. Precast concrete double-tee connections, part 2: shear behaviour. PCI Journal 2009; Spring: 97-115.

[21] Schoettler MJ, Belleri A, Zhang D, Restrepo JI, Fleischman RB. Preliminary results of the shaketable testing for the development of a diaphragm seismic design methodology. PCI Journal 2009; 12: $100-124$.

[22] Ferrara L, Toniolo G. Design approach for diaphragm action of roof decks in precast concrete buildings under earthquake. fib symposium "Taylor made concrete structures" 2008, Amsterdam, Netherlands, Walraven J. and Stoelhorst D. (Eds). 
[23] Biondini F, Dal Lago B, Toniolo G. Azione diaframma in strutture prefabbricate con pannelli di parete. $15^{\text {th }}$ ANIDIS Congress 2013; Padova, Italy (in Italian).

[24]Dal Lago B, Biondini F, Toniolo G. Seismic performance of precast concrete structures with energy dissipating cladding panel connection systems. Structural Concrete 2018, doi: 10.1002/suco.201700233.

[25] Dal Lago B, Ferrara L. Efficiency of mechanical floor connections on the diaphragm action of precast concrete floor/roof decks. $14^{\text {th }}$ International Symposium on Structural Engineering 2016, Beijing, China, 1: 469-476.

[26] Dal Lago B. Experimental and numerical assessment of the service behaviour of an innovative long-span precast roof element. International Journal of Concrete Structures and Materials 2017; 11(2): 261-273.

[27] Dal Lago B, Dal Lago A. New precast constructions for integrated complex urban interventions/ Neue fertigteilkonstruktionen für integrierte komplexe städtische interventionen. BFT International 2018; 84(4): 72-80.

[28]Dal Lago B, Toniolo G, Felicetti R, Lamperti Tornaghi M. End support connection of precast roof elements by bolted steel angles. Structural Concrete 2017; 18(5): 755-767.

[29] Belleri A, Torquati M, Riva P. Seismic performance of ductile connections between precast beams and roof elements. Magazine of Concrete Research 2014; 66(11): 553-562.

[30] Vintzeleou EN, Tassios TP. Behavior of dowels under cyclic deformations. ACI Structural Journal 1987; 84(1): 18-30.

[31] Tsoukantas SG, Tassios TP. Shear resistance of connections between reinforced concrete linear precast elements. ACI Structural Journal 1989; 86(3): 242-249.

[32]Dei Poli S, di Prisco M, Gambarova PG. Shear Response, deformations, and subgrade stiffness of a dowel bar embedded in concrete. ACI Structural Journal 1992; 89(6): 665-675.

[33] Psycharis IN, Mouzakis HP. Shear resistance of pinned connections of precast members to monotonic and cyclic loading. Engineering Structures 2012; 41: 413-427.

[34]Zoubek B, Isakovic T, Fahjan Y, Fischinger M. Cyclic failure analysis of the beam-to-column dowel connections in precast industrial buildings. Engineering Structures 2013; 52: 179-191.

[35] Magliulo G, Ercolino M, Cimmino M, Capozzi V, Manfredi G. Cyclic shear test on a dowel beam-to-column connection of precast buildings. Earthquakes and Structures 2015; 9(3): 541562.

[36] Negro P, Toniolo G. Design Guidelines for Connections of Precast Structures under the Seismic Action. EC-JRC-IPSC: Publications Office of the European Union, 2012.

[37]Ferrara L, Mola E, Negro P. Cyclic test on a full scale prototype of r/c one storey industrial building. $2^{\text {nd }}$ fib Congress 2006, Naples, Italy.

[38] Fischinger M, Kramar M, Isaković T. Cyclic response of slender RC columns typical of precast buildings. Bullein of Earthquake Engineering 2008; 6(3): 519-534. 
[39]Biondini F, Toniolo G. Probabilistic calibration and experimental validation of seismic design criteria for one storey concrete frames. Journal of Earthquake Engineering 2009; 13(4): 426-462.

[40] Negro P, Bournas DA, Molina J. Pseudodynamic Tests on a full-scale 3-storey precast concrete building: global response. Engineering Structures 2013; 57: 594-608.

[41] Bournas D A, Negro P, Molina J F. Pseudodynamic Tests on a full-scale 3-storey precast concrete building: behaviour of the mechanical connections and floor diaphragms. Engineering Structures 2013; 57: 609-627.

[42]Dal Lago B, Negro P, Dal Lago A. Seismic design and performance of dry-assembled precast structures with adaptable joints. Soil Dynamics and Earthquake Engineering 2018; 106: 182-195.

[43]Dal Lago B, Toniolo G, Lamperti Tornaghi M. Influence of different mechanical columnfoundation connections on the seismic performance of precast structures. Bulletin of Earthquake Engineering 2016; 14(12): 3485-3508.

[44]Dal Lago B, Muhaxheri M, Ferrara L. Numerical and experimental analysis of an innovative lightweight precast concrete wall. Engineering Structures 2017; 137: 204-222.

[45]Biondini F, Dal Lago B, Toniolo, G. Role of wall panel connections on the seismic performance of precast structures. Bulletin of Earthquake Engineering 2013; 11: 1061-1081.

[46] Magliulo G, Ercolino M, Manfredi G. Influence of cladding panels on the first period of onestory precast buildings. Bulletin of Earthquake Engineering 2014; 13(5): 1531-1555.

[47] Negro P, Lamperti Tornaghi M. Seismic response of precast structures with vertical cladding panels: the SAFECLADDING experimental campaign. Engineering Structures 2017; 132: 205228.

[48] Toniolo G, Dal Lago B. Conceptual design and full-scale experimentation on cladding panel connection systems of precast structures. Earthquake Engineering \& Structural Dynamics 2017; 46(14): 2565-2586.

[49] Takeda T, Sozen MA, Nielsen NN. Reinforced Concrete Response to Simulated Earthquakes. ASCE Journal of the Structural Division 1970; 96(12): 2557-2573.

[50] MIDAS Information Technology. MIDAS/Gen-General structure design system. MIDAS/Gen Version 8.25 Analysis and Design Manual, 2013, Seongnam, South Korea.

[51] Mander J, Priestley M, Park R. Theoretical Stress-Strain Model for Confined Concrete. ASCE Journal of Structural Engineering 1988; 114(8).

[52] Menegotto M, Pinto P E. Method of analysis of cyclically loaded RC plane frames including changes in geometry and non-elastic behavior of elements under normal force and bending. Preliminary Report IABSE 1973; 13.

[53]Zoubek B, Fischinger M, Isaković T. Cyclic response of hammer-head strap cladding-tostructure connections used in RC precast buildings. Engineering Structures 2016; 119: 135-148.

[54] Colombo A, Ferrara L. Seismic structural design of RC buildings Progettazione strutturale di un edificio industriale prefabbricato in zona sismica. AICAP-ASSOBETON design manual, 2008. 